\title{
Clumped isotopologue fractionation by microbial cultures performing the anaerobic oxidation of methane
}

\author{
Shuhei Ono ${ }^{\mathrm{a}, *}$, Jeemin H. Rhim ${ }^{\mathrm{a}}$, Danielle S. Gruen ${ }^{\mathrm{a}, 1}$, Heidi Taubner ${ }^{\mathrm{b}}$, \\ Martin Kölling ${ }^{\mathrm{b}}$, Gunter Wegener ${ }^{\mathrm{b}, \mathrm{c}}$ \\ ${ }^{a}$ Department of Earth, Atmospheric and Planetary Science, Massachusetts Institute of Technology, Cambridge, MA, USA \\ ${ }^{\mathrm{b}}$ MARUM Center for Marine Environmental Science, University of Bremen, Bremen, Germany \\ ${ }^{\mathrm{c}}$ Max Planck Institute for Marine Microbiology, Bremen, Germany
}

Received 6 March 2020; accepted in revised form 13 October 2020; Available online 22 October 2020

\begin{abstract}
Methane is abundant in marine subsurface sediments, sourced from microbial or thermocatalytic production. The relative composition of its isotopologues $\left({ }^{12} \mathrm{CH}_{4},{ }^{13} \mathrm{CH}_{4},{ }^{12} \mathrm{CH}_{3} \mathrm{D}\right.$ and $\left.{ }^{13} \mathrm{CH}_{3} \mathrm{D}\right)$ is used to infer its sources and sinks. The anaerobic oxidation of methane (AOM) is an important methane sink reaction carried out by consortia of anaerobic methanotrophic archaea (ANME) and partner bacteria in the presence of methane and sulfate. We investigated the methane isotopologue fractionations during AOM in experiments with cultures of ANME-1 archaea and partner bacteria obtained from hydrothermally heated gas-rich sediments of the Guaymas Basin. During partial methane consumption in four sets of experiments, residual methane became enriched in ${ }^{13} \mathrm{CH}_{4}$ and ${ }^{12} \mathrm{CH}_{3} \mathrm{D}$, following kinetic fractionations from 11.1 to $18.3 \%$ and from 117 to $180 \%$, respectively. Results from one set of experiments with $\mathrm{D}$-depleted medium water $(\delta \mathrm{D}=-200 \%$, whereas the control was 55\%o) suggest the potential reversibility during the methane activation step, which would contribute to equilibrium as opposed to kinetic fractionations. The value of $\Delta^{13} \mathrm{CH}_{3} \mathrm{D}$ (the abundance of ${ }^{13} \mathrm{CH}_{3} \mathrm{D}$ with respect to that expected from stochastic distribution) increased toward and beyond (up to 8.4\%o) the value expected for isotopologue equilibrium $\left(5.3 \%\right.$ at $\left.37{ }^{\circ} \mathrm{C}\right)$. The kinetic clumped isotopologue fractionation (difference between ${ }^{13} \mathrm{CH}_{3} \mathrm{D} /{ }^{12} \mathrm{CH}_{3} \mathrm{D}$ and ${ }^{13} \mathrm{CH}_{4} /{ }^{12} \mathrm{CH}_{4}$ fractionations) of 4.8 to $12.8 \%$ is in contrast with our previous observation of little to no clumped isotopologue effect during aerobic methane oxidation. Our results demonstrate that AOM can contribute to near-equilibrium $\Delta^{13} \mathrm{CH}_{3} \mathrm{D}$ values observed in marine sediments and ${ }^{13} \mathrm{CH}_{3} \mathrm{D}$ systematics can be used to distinguish aerobic versus anaerobic methanotrophic processes in nature.
\end{abstract}

(C) 2020 Elsevier Ltd. All rights reserved.

Keywords: Methane; Isotopologue; AOM; Anerobic oxidation; Clumped; 13CH3D; Fractionation

\footnotetext{
* Corresponding author.

E-mail addresses: sono@mit.edu (S. Ono),jrhim@alum.mit.edu (J.H. Rhim), dgruen@alum.mit.edu (D.S. Gruen), htaubner@ marum.de (H. Taubner), koelling@uni-bremen.de (M. Kölling), gwegener@mpi-bremen.de (G. Wegener).

1 Present address; Department of Surgery, University of Pittsburgh, Pittsburgh, PA 15213, USA.
}

\section{INTRODUCTION}

Marine sediments store about 500-5000 Gt of methane (Buffett and Archer, 2004; Milkov, 2004). This methane derives from three main sources. In deep marine sediments, typically a few $\mathrm{km}$ or deeper, thermogenic methane is produced via the thermocatalytic decay of organic matter (e.g., Tissot et al., 1974). In shallower anoxic sediments and petroleum reservoirs, typically below ca. $60-80{ }^{\circ} \mathrm{C}$, archaea produce methane as a metabolic product (Wilhelms et al., 
2001; Reeburgh, 2007; Inagaki et al., 2015). A minor component of marine methane may originate from abiotic methane production during the alteration of seafloor rocks (e.g., McDermott et al., 2015; Wang et al., 2018; Klein et al., 2019). The origins of methane are often inferred based on its carbon $\left({ }^{13} \mathrm{C} /{ }^{12} \mathrm{C}\right)$ and hydrogen $(\mathrm{D} / \mathrm{H})$ isotopic compositions (e.g., Schoell, 1980; Whiticar, 1999). Methane that is depleted in ${ }^{13} \mathrm{C}$ by $<-45 \%$ (with respect to $\mathrm{PDB}$ ) is usually interpreted as microbial in origin. Thermogenic methane is usually more ${ }^{13} \mathrm{C}$-enriched. The boundaries between these values are not well defined.

In addition to bulk isotope ratios, the relative abundance of rare methane isotopologues with multiple heavy isotope substitutions (e.g., ${ }^{13} \mathrm{CH}_{3} \mathrm{D}$ and ${ }^{12} \mathrm{CH}_{2} \mathrm{D}_{2}$ ), also known as clumped isotopologues, has been proposed as a tool to gauge the temperature of methane generation or isotopic re-equilibration (Stolper et al., 2014ab; Wang et al., 2015; Young et al., 2017). This approach is based on the isotopologue exchange reaction:

${ }^{13} \mathrm{CH}_{4}+{ }^{12} \mathrm{CH}_{3} \mathrm{D} \leftrightarrow{ }^{13} \mathrm{CH}_{3} \mathrm{D}+{ }^{12} \mathrm{CH}_{4}$

The equilibrium constant of this reaction primarily depends on temperature, approaching unity at high temperatures $\left(1.0002\right.$ at $\left.1,000^{\circ} \mathrm{C}\right)$ and expected to be about 1.0057 at $25^{\circ} \mathrm{C}$. The effects of pressure, hydration, salinity etc. are expected to be small but have not been carefully examined. Thus, precise measurements of four isotopologues of methane yield the apparent temperature that is expected if isotopologues were thermally equilibrated. Studies thus far have shown that the clumped isotopologue composition of methane from subsurface environments (e.g., marine sediment porewater, natural gas deposits) often yields reasonable formation temperatures, whereas methane sampled from surface environments (e.g., ruminants, lakes, and swamps) is characterized by clear kinetic signals that yield apparent clumped isotopologue temperatures much higher than the environmental temperatures (Stolper et al., 2014b, 2015; Wang et al., 2015; Douglas et al., 2017, 2020; Young et al., 2017; Ash et al., 2019; Giunta et al., 2019).

The kinetic isotopologue signals from surface methane are consistent with those from laboratory culture experiments, in which methanogens consistently produced methane with non-equilibrium isotopologue compositions (Wang et al., 2015; Douglas et al., 2017, 2020; Young et al., 2017; Gruen et al., 2018; Stolper et al., 2015). Previous studies have also investigated the clumped methane isotopologue fractionation during sink reactions, including aerobic methane oxidation (Wang et al., 2016) and gas phase methane oxidation by $\mathrm{OH}$ and $\mathrm{Cl}$ radicals (Whitehill et al., 2017; Joelsson et al., 2014, 2016). Both processes fractionate isotopologues in such a way that the remaining methane is more depleted in ${ }^{13} \mathrm{CH}_{3} \mathrm{D}$, which brings ${ }^{13} \mathrm{CH}_{3} \mathrm{D}$ abundance away from that expected for equilibrium. Therefore, questions remain as to how methane with apparent equilibrium isotopologue signals can be produced in marine subsurface environments. It has been hypothesized that methane with equilibrium isotopologue composition is linked to high reversibility of slow methanogenesis in low-energy environments (Stolper et al.,
2015; Wang et al., 2015; Okumura et al., 2016) and/or the result of the anaerobic oxidation of methane (AOM) (Okumura et al., 2016; Ash et al., 2019; Giunta et al., 2019). A question remains whether AOM is required to produce equilibrium $\delta \mathrm{D}$ and $\Delta^{13} \mathrm{CH}_{3} \mathrm{D}$ (and $\Delta^{12} \mathrm{CH}_{2} \mathrm{D}_{2}$ ) signals. We note that similar questions were raised for sulfur isotope systems whether near-equilibrium ${ }^{34} \mathrm{~S} /{ }^{32} \mathrm{~S}$ fractionation requires oxidative sulfur cycles or can be produced by microbial sulfate reduction alone (e.g., Canfield and Thamdrup, 1994; Sim et al., 2011).

The AOM is performed by anaerobic methane-oxidizing archaea (ANME) that form consortia with sulfate-reducing bacteria (reviewed in Knittel et al., 2019). The ANME are relatives of methanogens and they reverse the entire methanogenesis pathway for methane oxidation (Hallam et al., 2004; Meyerdierks et al., 2010). The effect of AOM on carbon and hydrogen isotopic compositions of methane has been investigated in multiple studies. At seawater sulfate concentrations $(28 \mathrm{mM})$, AOM has kinetic carbon and hydrogen isotope fractionations resulting in the enrichment of ${ }^{13} \mathrm{C}$ and $\mathrm{D}$ in the remaining methane (Holler et al., 2009). In contrast, AOM at low sulfate concentrations results in ${ }^{13} \mathrm{C}$-depletion in the remaining methane. The decreasing methane carbon isotopic compositions were explained as isotopic equilibration between methane and inorganic carbon mediated by AOM (Yoshinaga et al., 2014). The different availability of sulfate may explain the variant methane isotope patterns observed in AOM active marine sediments (Borowski et al., 1997; Pohlman et al., 2008; Yoshinaga et al., 2014). Similar studies for the hydrogen isotope systematics have not been published.

This study experimentally examines the bulk $\left({ }^{13} \mathrm{C} /{ }^{12} \mathrm{C}\right.$ and $\mathrm{D} / \mathrm{H})$ and clumped isotopologue $\left({ }^{13} \mathrm{CH}_{3} \mathrm{D}\right)$ fractionation of AOM. The cultures used in this study consist of consortia of ANME of the ANME-1 clade and the partner bacteria of the Seep-SRB2 group (Holler et al., 2011a; Krukenberg et al., 2018). To reveal the isotope fractionation patterns of AOM, we measured the relative abundance of four isotopologues, ${ }^{12} \mathrm{CH}_{4},{ }^{13} \mathrm{CH}_{4},{ }^{12} \mathrm{CH}_{3} \mathrm{D}$ and ${ }^{13} \mathrm{CH}_{3} \mathrm{D}$ of methane remaining in the cultures. The fractionation of ${ }^{13} \mathrm{CH}_{3} \mathrm{D}$ for AOM is characteristically different from that of aerobic methane oxidation reported in a previous study (Wang et al., 2016). Our study suggests that AOM may contribute to, although is not necessarily required for, the near-equilibrium isotopologue signals observed in marine environments.

\section{METHODS}

\subsection{Description of culture experiments}

All experiments were performed with sediment-free $37^{\circ} \mathrm{C}$ AOM enrichment cultures obtained from hydrothermally-heated, gas-rich sediments of the Guaymas Basin sampled during RV Atlantis cruise AT15-56 with the submarine ALVIN in December 2009. The cultivation procedures, physiological properties and microbial compositions of this culture have been described before (Holler et al., 2011a; Wegener et al., 2016; Krukenberg et al., 2018; Laso-Pérez et al., 2018). 
Table 1

Results from incubation experiments with the AOM cultures. Errors for $\Delta^{13} \mathrm{CH}_{3} \mathrm{D}$ values are $95 \%$ confidence intervals for TILDAS measurements ( $\mathrm{N}=4$ to 8 ).

\begin{tabular}{|c|c|c|c|c|c|c|c|c|}
\hline Sample ID & time (days) & $\begin{array}{l}\mathrm{CH}_{4} \text { oxidized } \\
(\%)\end{array}$ & $\begin{array}{l}\text { sulfide } \\
(\mathrm{mM})\end{array}$ & $\begin{array}{l}\delta \mathrm{D}_{\mathrm{H} 2 \mathrm{O}} \\
(\%)\end{array}$ & $\delta^{13} \mathrm{C}_{\text {DIC }}(\% o)$ & $\delta^{13} \mathrm{C}_{\mathrm{CH} 4}(\% o)$ & $\begin{array}{l}\delta \mathrm{D}_{\mathrm{CH} 4} \\
(\% \circ)\end{array}$ & $\begin{array}{l}\Delta^{13} \mathrm{CH}_{3} \mathrm{D} \\
(\%)\end{array}$ \\
\hline \multicolumn{6}{|c|}{$\begin{array}{l}\text { Initial } \mathrm{CH}_{4} \text { from cylinder for } \mathrm{C} \text { and } \mathrm{B} \text { series } \\
\mathrm{C} \text { series }\end{array}$} & -36.74 & -166.02 & $1.63 \pm 0.64$ \\
\hline $\mathrm{C} 0$ & 0 & 0.0 & 0.39 & n.m. & n.m. & n.m. & n.m. & n.m. \\
\hline $\mathrm{Cl}$ & 1 & 0.5 & 0.46 & -48.2 & -9.2 & -37.12 & -165.14 & $1.79 \pm 0.32$ \\
\hline $\mathrm{C} 2$ & 8 & 8.1 & 1.50 & -48.8 & -10.3 & -35.44 & -153.75 & $2.13 \pm 0.28$ \\
\hline $\mathrm{C} 3$ & 14 & 12.6 & 2.14 & -48.7 & -11.2 & -34.23 & -142.09 & $2.35 \pm 0.43$ \\
\hline $\mathrm{C} 4$ & 21 & 21.5 & 3.36 & -48.6 & -12.1 & -33.05 & -130.19 & $3.05 \pm 0.46$ \\
\hline $\mathrm{C} 5$ & 28 & 31.2 & 4.68 & -48.6 & -13.0 & -31.16 & -111.49 & $3.86 \pm 0.33$ \\
\hline C6 & 35 & 34.3 & 5.11 & -48.6 & -13.4 & -30.68 & -108.10 & $4.37 \pm 0.23$ \\
\hline $\mathrm{C} 7$ & 42 & 35.6 & 5.29 & -48.6 & -13.7 & -29.05 & -92.67 & $5.06 \pm 0.25$ \\
\hline \multicolumn{9}{|l|}{ B-series } \\
\hline B0 & 0 & 0.0 & 0.32 & n.m. & n.m. & -36.90 & -166.02 & $1.74 \pm 0.22$ \\
\hline B1 & 4 & 5.2 & 1.04 & -53.6 & -13.3 & -36.07 & -158.89 & $2.07 \pm 0.42$ \\
\hline B2 & 11 & 13.4 & 2.18 & -53.5 & -14.1 & -34.01 & -141.00 & $2.65 \pm 0.28$ \\
\hline B3 & 18 & 24.1 & 3.64 & -53.6 & -16.4 & -32.33 & -126.44 & $2.98 \pm 0.18$ \\
\hline B4 & 25 & 35.1 & 5.14 & -53.7 & -16.7 & -31.19 & -117.09 & $3.34 \pm 0.18$ \\
\hline B5 & 32 & 43.0 & 6.18 & -53.7 & -18.0 & n.m. & n.m. & n.m. \\
\hline B6 & 39 & 46.6 & 6.71 & -53.5 & -18.6 & -26.71 & -80.47 & $4.47 \pm 0.10$ \\
\hline B7 & 46 & 61.0 & 8.68 & -53.5 & -20.2 & -21.81 & -37.72 & $5.47 \pm 0.20$ \\
\hline B8 & 54 & 55.0 & 7.86 & -53.6 & -19.5 & n.m. & $n . m$. & n.m. \\
\hline B9 & 60 & 69.9 & 9.86 & -53.7 & -20.7 & -18.90 & -6.39 & $7.07 \pm 0.22$ \\
\hline B10 & 67 & 75.2 & 10.64 & -53.8 & -20.6 & n.m. & $n . m$. & $n . m$. \\
\hline
\end{tabular}

Abiotic controls

\begin{tabular}{|c|c|c|c|c|c|c|c|c|}
\hline $\mathrm{X} 1$ & 1 & n.m. & 0 & -48.6 & -7.2 & -36.82 & -165.95 & $1.87 \pm 0.49$ \\
\hline $\mathrm{X} 2$ & 14 & n.m. & 0 & -48.5 & -8.4 & -36.68 & -165.78 & $1.41 \pm 0.38$ \\
\hline $\mathrm{X} 3$ & 41 & n.m. & 0 & -48.5 & -8.7 & -36.31 & -164.93 & $1.45 \pm 0.25$ \\
\hline \multicolumn{6}{|c|}{$\begin{array}{l}\text { Initial } \mathrm{CH}_{4} \text { from cylinder for } \mathrm{D} \text { and } \mathrm{N} \text { series } \\
\text { D-series }\end{array}$} & -42.00 & -189.56 & $2.5 \pm 0.93$ \\
\hline D1 & 0 & 0.0 & 0.44 & -202.2 & -17.9 & -42.12 & -189.82 & $2.67 \pm 0.29$ \\
\hline D2 & 3 & 1.7 & 0.69 & -199.6 & -18.6 & -42.00 & -187.68 & $2.95 \pm 0.30$ \\
\hline D3 & 7 & 7.1 & 1.49 & -199.8 & -20.1 & -41.42 & -182.54 & $3.5 \pm 0.23$ \\
\hline D4 & 11 & 12.9 & 2.36 & -199.9 & -22.3 & -40.51 & -174.37 & $3.7 \pm 0.18$ \\
\hline D5 & 15 & 20.9 & 3.56 & -200.3 & -24.0 & -39.61 & -166.58 & $4.1 \pm 0.32$ \\
\hline D6 & 19 & 26.5 & 4.40 & -200.2 & -25.2 & n.m. & n.m. & n.m. \\
\hline D7 & 24 & 35.3 & 5.71 & -199.3 & -26.5 & -36.89 & -146.01 & $4.68 \pm 0.36$ \\
\hline D8 & 28 & 49.7 & 7.85 & -199.7 & -28.3 & -36.04 & -138.37 & $5.19 \pm 0.22$ \\
\hline D9 & 31 & 50.1 & 7.93 & -200.6 & -28.6 & n.m. & n.m. & $n . m$. \\
\hline D10 & 35 & 61.6 & 9.64 & -199.4 & -30.1 & -32.45 & -107.65 & $6.36 \pm 0.18$ \\
\hline D11 & 49 & 81.8 & 12.65 & -201.0 & -31.1 & -30.34 & -79.77 & $8.46 \pm 0.21$ \\
\hline \multicolumn{9}{|c|}{$N$-series } \\
\hline N1 & 0 & 0.0 & 0.36 & -55.5 & -17.8 & -42.09 & -189.82 & $2.54 \pm 0.46$ \\
\hline N2 & n.m. & n.m. & 0.65 & -55.0 & -18.5 & n.m. & n.m. & n.m. \\
\hline N3 & 7 & 7.1 & 1.42 & -55.0 & -19.7 & -41.57 & -180.64 & $3.17 \pm 0.28$ \\
\hline N4 & n.m. & $n . m$. & 3.20 & n.m. & -23.4 & $n . m$. & n.m. & n.m. \\
\hline N5 & 24 & 23.6 & 3.89 & -54.8 & -24.3 & -38.82 & -156.82 & $3.35 \pm 0.33$ \\
\hline N6 & 31 & 47.5 & 7.45 & -55.0 & -28.2 & -35.28 & -126.22 & $4.43 \pm 0.34$ \\
\hline
\end{tabular}

The analysis of methane clumped isotopologue composition requires a relatively large gas sample of $40 \mu \mathrm{mol}$ or more methane. To meet this requirement, we performed four different $(\mathrm{C}, \mathrm{B}, \mathrm{D}$ and $\mathrm{N})$ series of 6 to 11 replicate incubations each (Table 1). Experiment $\mathrm{C}$ - and B-series were run as duplicates (the same starting methane and car- ried out at the same time). D- and N-series used the same starting methane but D-series used D-depleted water medium $\left(\delta \mathrm{D}_{\mathrm{H} 2 \mathrm{O}}=-200 \%\right.$, Table 1$)$ to test the potential exchange of $\mathrm{H}$ isotopes between water and methane. $\mathrm{N}$-series (normal D-experiment, $\delta \mathrm{D}_{\mathrm{H} 2 \mathrm{O}}=-55 \%$ ) is a control for D-series that was run simultaneously with the 
D-series. Experiment X-series are the abiotic control experiments run at the same time as B- and C-series experiments. These control experiments were not inoculated in order to test the potential isotopologue fractionation during sample processing.

For the experiment, a suitable amount of culture targeting a methane-dependent sulfate reduction rate of 100 $150 \mu \mathrm{mol} \mathrm{l}^{-1} \mathrm{~d}^{-1}$ was homogenized by stirring in an anoxic chamber free of hydrogen gas. The homogenized culture was supplied with fresh artificial saline medium with seawater sulfate concentration $(28 \mathrm{mM})$ and $10 \mathrm{mM}$ dissolved inorganic carbon (DIC). The culture was then equally distributed to $70-\mathrm{ml}$ culture vials and filled up completely with culture medium. For the experiment with low $\mathrm{D}-\mathrm{H}_{2} \mathrm{O}$ (Dseries), the culture medium was prepared with $200 \mathrm{ml} \mathrm{D}$ depleted water $(\leq 1 \mathrm{ppm}$ D, Sigma-Aldrich) and $800 \mathrm{ml}$ ultrapure water.

The completely filled and closed culture bottles were removed from the chamber and $7 \mathrm{ml}$ of the medium volume was replaced with $20 \mathrm{ml}$ of methane: $\mathrm{CO}_{2}$ (90:10) gas mixture that supplied $0.75 \mathrm{mmol}$ methane to the culture. Hence, all experiments were performed under excess of sulfate (1.76 mmol per vial). All bottles were transferred into a $37^{\circ} \mathrm{C}$ incubator equipped with a shaking table operated at $70 \mathrm{rpm}$. Due to constant agitation of the bottles and the slow AOM rate, all reactants and products of AOM including methane isotopologues are considered to be equilibrated between liquid and headspace. Sulfide concentrations for samples were measured every 3-5 days from $0.1 \mathrm{ml}$ sample volume in a miniaturized $4 \mathrm{ml}$ copper sulfate assay (Cord-Ruwish, 1985). The increase of sulfide concentrations was used to determine the amount of methane consumed in the samples, assuming 1:1 stoichiometry between methane oxidation and sulfide production, according to the reaction stoichiometry, $\mathrm{CH}_{4}+\mathrm{SO}_{4}^{2-} \rightarrow$ $\mathrm{HCO}_{3}^{-}+\mathrm{HS}^{-}+\mathrm{H}_{2} \mathrm{O}$.

At the beginning of the experiment and when reaching designated sulfide concentrations (i.e., reaching specific partial methane consumption values), these bottles were sampled for different measurements. The liquid phase was sampled for the measurement of DIC isotopic compositions (filtration of $6 \mathrm{ml}$ medium into Exetainer ${ }^{\circledR}$ vials, Labco) and the determination of hydrogen isotopic composition of water (filtration of $2 \mathrm{ml}$ into Exetainer). Then, the culture headspace was completely replaced with anoxic DICfree medium, while a syringe concurrently collected the headspace (methane). This gas was transferred to another culture vial that was filled with $10 \% \mathrm{NaOH}$ solution by displacement.

\subsection{Isotope ratio analyses}

Isotope ratios are reported using standard deltanotation:

$\delta^{\mathrm{i}} \mathrm{A}=\frac{\left({ }^{\mathrm{i}} \mathrm{A} /{ }^{\mathrm{j}} \mathrm{A}\right)_{\text {sample }}}{\left({ }^{\mathrm{i}} \mathrm{A} /{ }^{\mathrm{j}} \mathrm{A}\right)_{\text {reference }}}-1$

where, ${ }^{\mathrm{i}} \mathrm{A}$ is ${ }^{2} \mathrm{H}$ (symbol $\mathrm{D}$ is used as deuterium), ${ }^{13} \mathrm{C}$, or ${ }^{18} \mathrm{O}$, for the isotope ratio $\left({ }^{\mathrm{i}} \mathrm{A} /{ }^{\mathrm{j}} \mathrm{A}\right),{ }^{2} \mathrm{H} /{ }^{1} \mathrm{H},{ }^{13} \mathrm{C} /{ }^{12} \mathrm{C}$ or
${ }^{18} \mathrm{O} /{ }^{16} \mathrm{O}$, respectively. Following IUPAC recommendations, the commonly used multiplication factor of 1000 is omitted from the definition since it technically belongs to per mil (\%o) (Coplen, 2011).

Hydrogen isotopic compositions of medium water $\left(\delta \mathrm{D}_{\mathrm{H} 2 \mathrm{O}}\right)$ were measured by cavity ring-down spectrometry (Picarro L-2130-i). The geometric mean and relative standard deviations are calculated from the last three of nine $7 \mu \mathrm{l}$ injections of a $0.2 \mu \mathrm{m}$-filtered water sample. The results are calibrated against the VSMOW2 and SLAP2 isotope standards. For calibration, we used 39:1, 19:1, 9:1 and 5:1 mixtures of our lab standard "LMOW" $\left(\delta^{18} \mathrm{O}=+0.10 \%\right.$, $\delta \mathrm{D}=+0.45 \%$ on the VSMOW2-SLAP2 scale) and SLAP2.

Carbon isotopic compositions of DIC were determined by isotope ratio infrared spectrometry (IRIS; Thermo Scientific Delta Ray IRIS with URI connect and Cetac ASX-7100 Autosampler). Measurement vials (12 ml Exetainer ${ }^{\circledR}$ vials; Labco) were filled with $100 \mu 1$ phosphoric acid $(45 \%)$ and headspace was flushed and replaced with synthetic air for 3 minutes. Samples $(1 \mathrm{ml}$ each) were injected via a syringe and kept at room temperature for transformation of DIC into $\mathrm{CO}_{2}$. After 10 hours of equilibration, the carbon isotopic composition of $\mathrm{CO}_{2}$ of each sample was analyzed.

\subsection{Methane isotopologue analysis}

Samples of methane $(>40 \mu \mathrm{mol})$ were purified by cryogenic distillation to remove water and $\mathrm{CO}_{2}$, followed by cryofocusing-preparative gas chromatography (Wang et al., 2015, 2016). Preparative gas chromatography is equipped with a packed column (Carboxen-1000, $5^{\prime} \times 1 / 8^{\prime \prime}$, Supelco) held at $30^{\circ} \mathrm{C}$ with helium carrier gas. The eluted methane was trapped on activated charcoal at liquid nitrogen temperature. The relative abundances of ${ }^{12} \mathrm{CH}_{4},{ }^{13} \mathrm{CH}_{4}$, ${ }^{12} \mathrm{CH}_{3} \mathrm{D}$ and ${ }^{13} \mathrm{CH}_{3} \mathrm{D}$ were measured using tunable infrared laser direct absorption spectroscopy (TILDAS) described previously by Ono et al. (2014).

Results in Table 1 show 95\% confidence interval for the spectroscopic measurements, typically 0.2 to $0.4 \%$ for $\Delta^{13} \mathrm{CH}_{3} \mathrm{D}$ values. This does not include potential fractionation during sample preparation. Data for abiotic control experiments (X-series, Table 1) show that the errors for sample preparation processes are comparable to the $95 \%$ confidence above. Most samples were measured by the recycle mode, in which sample $\mathrm{CH}_{4}$ was recovered from the TILDAS absorption cell to the cold trap, and reintroduced to TILDAS for 6 to 10 times. This allows repeated comparison of sample against reference gas. Thus, precision is not necessarily a function of sample size. Isotope values are reported using standard delta notation against $\mathrm{PDB}$ and SMOW for the ratios ${ }^{13} \mathrm{C} /{ }^{12} \mathrm{C}$ and $\mathrm{D} / \mathrm{H}$, respectively. This isotope scale was calibrated by the measurements of NGS-1 and NGS-3 (Wang et al., 2016).

We define $\Delta^{13} \mathrm{CH}_{3} \mathrm{D}$ value as a measure of the abundance of ${ }^{13} \mathrm{CH}_{3} \mathrm{D}$ relative to stochastic distributions (Ono et al., 2014):

$\Delta{ }^{13} \mathrm{CH}_{3} \mathrm{D}=\ln \left(\frac{{ }^{13} \mathrm{CH}_{3} \mathrm{D}}{{ }^{12} \mathrm{CH}_{3} \mathrm{D}} \cdot \frac{{ }^{12} \mathrm{CH}_{4}}{{ }^{13} \mathrm{CH}_{4}}\right)$ 
The relationship between $\Delta^{13} \mathrm{CH}_{3} \mathrm{D}$ values and apparent methane generation temperatures is based on the formula

$$
\begin{aligned}
\Delta{ }^{13} \mathrm{CH}_{3} \mathrm{D}(\mathrm{T})= & -0.11006\left(\frac{1000}{T}\right)^{3} \\
& +1.04151\left(\frac{1000}{T}\right)^{2} \\
& -0.55235\left(\frac{1000}{T}\right)
\end{aligned}
$$

where $T$ is temperature in Kelvin. The equation is approximated from the solution based on the fundamental vibrational frequencies calculated by density functional theory (Whitehill et al., 2017). Eq. (4) produces lower $\Delta^{13} \mathrm{CH}_{3} \mathrm{D}$ values by $0.1 \pm 0.01 \%$ (for the temperature range from 20 to $160{ }^{\circ} \mathrm{C}$ ) compared to the recent calibration by Eldridge et al. (2019).

\subsection{Calculation of isotope fractionation factors}

Isotope fractionation factors ( $\alpha$ values) are calculated based on the conventional Rayleigh equation (Mariotti et al., 1981):

$\ln \left(\delta^{13} \mathrm{C}+1\right)=\ln \left(\delta^{13} \mathrm{C}_{0}+1\right)+\left({ }^{13} \alpha-1\right) \cdot \ln f \quad$ and,

$\ln (\delta \mathrm{D}+1)=\ln \left(\delta \mathrm{D}_{0}+1\right)+\left({ }^{2} \alpha-1\right) \cdot \ln f$.

where $f$ is the fraction of $\mathrm{CH}_{4}$ remaining, and ${ }^{13} \alpha$ and ${ }^{2} \alpha$ are the kinetic isotope fractionation factors for carbon $\left({ }^{13} \mathrm{C} /{ }^{12} \mathrm{C}\right)$ and hydrogen $(\mathrm{D} / \mathrm{H})$ isotopes, respectively, and $\delta^{13} C_{0}$ and $\delta D_{0}$ are initial isotope compositions of methane. The kinetic fractionation factor is the ratio of the rate constants for ${ }^{13} \mathrm{CH}_{4}$ or ${ }^{12} \mathrm{CH}_{3} \mathrm{D}$ relative to ${ }^{12} \mathrm{CH}_{4}$ (e.g., $\left.{ }^{13} \alpha=k_{13 \mathrm{CH} 4} / k_{12 \mathrm{CH} 4}\right)$. The $\varepsilon$ symbol is used to represent the departure of fractionation factors from unity $\left({ }^{13} \varepsilon=1-{ }^{13} \alpha\right.$ or $\left.{ }^{2} \varepsilon=1-{ }^{2} \alpha\right)$. Equations (5) and (6) are exact solutions when $f$ is quantified as the fraction of ${ }^{12} \mathrm{CH}_{4}$ remaining (as opposed to total methane isotopologues). Fractionations (slopes) and their uncertainty are calculated by weighted least square method of York et al. (2004). Errors for $\mathrm{H}_{2} \mathrm{~S}$ concentrations are estimated to be $5 \%$ of measured value. For isotopologue ratios, 95\% confidence interval for 4 to 8 measurements were used to estimate errors (Table 1; Fig. 1).

The corresponding equation for the $\Delta^{13} \mathrm{CH}_{3} \mathrm{D}$ value is:

$\Delta^{13} \mathrm{CH}_{3} \mathrm{D}=\Delta^{13} \mathrm{CH}_{3} \mathrm{D}_{0}+\left({ }^{13,2} \alpha-{ }^{13} \alpha-{ }^{2} \alpha+1\right) \cdot \ln f$

where, ${ }^{13,2} \alpha$ is the isotopologue fractionation factor for ${ }^{13} \mathrm{CH}_{3} \mathrm{D}$ relative to ${ }^{12} \mathrm{CH}_{4}$ (Wang et al., 2016). According to the rule of geometric mean (Bigeleisen, 1955), ${ }^{13,2} \alpha$ is approximately equal to the product of ${ }^{13} \alpha$ and ${ }^{2} \alpha\left({ }^{13,2} \alpha \simeq^{13} \alpha^{2} \alpha\right)$. We define the deviation from the rule of geometric mean as the kinetic clumped isotopologue factor $(\gamma)$ :

$$
{ }^{13,2} \alpha=\gamma \cdot{ }^{13} \alpha \cdot{ }^{2} \alpha
$$

For bond breaking processes, the reduction of the zeropoint energy $(\triangle \mathrm{ZPE})$ at transition state produces $\gamma$ values less than unity (Whitehill et al., 2017) as discussed in Section 4.2.

\section{RESULTS}

Results of the experiments are reported in Table 1. Throughout the course of each experiment, AOM partially consumed methane, as indicated by increasing sulfide concentrations. The AOM consortia consumed 100-160 $\mu \mathrm{mol}$ of methane per liter per day, translating into about $0.9 \%$ to $1.6 \%$ of the supplied methane. The rates of AOM remained largely constant, due to the inherently slow growth of AOM communities with doubling times of about 90 days. After specific time intervals, single bottles were analyzed for headspace methane concentrations (see methods).

All four series of experiments showed kinetic isotope fractionations with progressive enrichment of the residual methane in isotopologues containing heavy $\left({ }^{13} \mathrm{C}\right.$ and $\left.\mathrm{D}\right)$ isotopes (Fig. 1). Fig. 1 illustrates the derived fractionations for the carbon isotope of $11.1 \%$ to $18.3 \%$ and hydrogen isotope fractionation of $117 \%$ to $180 \%$ (Fig. 1; Table 2). Experiments carried out at the same time and using the same starting culture (i.e., B- versus C-series, and N- versus $\mathrm{D}$-series) yielded consistent fractionation factors, but the two sets of experiments yielded somewhat different fractionation factors. One reason for the different fractionation factors might be the slightly lower $\mathrm{pH}$ value in the later experiments (6.8 versus 7.2). This modification was introduced in between the two experiments to avoid carbonate precipitation in the cultures. Last two data points for Dseries are not on the linear regression trend. Its implication to reversibility is discussed in Section 4.1 and Appendix A. During the course of the experiments, the $\Delta^{13} \mathrm{CH}_{3} \mathrm{D}$ values of methane increased from $2.0 \pm 0.5 \%$ to up to $8.5 \%$, which is higher than the value expected for isotopologue equilibrium at experimental temperature $\left(\Delta^{13} \mathrm{CH}_{3} \mathrm{D}_{\text {eq. }}=5.4 \%\right.$ at $\left.37^{\circ} \mathrm{C}\right)$ (Table 1; Fig. 1$)$.

\section{DISCUSSION}

\subsection{Kinetic isotopologue fractionations were observed during AOM}

The observed ranges of kinetic fractionations for ${ }^{13} \mathrm{C} /{ }^{12} \mathrm{C}$ and $\mathrm{D} / \mathrm{H}$ ratios (from $11.1 \%$ to $18.3 \%$ and from $117 \%$ to $180 \%$, respectively) are largely consistent with the previous study, where AOM cultures were adapted to and experimented at lower temperatures $\left(12\right.$ and $\left.20^{\circ} \mathrm{C}\right)$ (Fig. 2; Holler et al., 2009).

In order to evaluate if the observed isotopologue effect is entirely kinetic, the potential reversibility of AOM was investigated with cultures using media with different $\delta \mathrm{D}$ compositions (D- and N-series, Table 1). The experiment with a strongly D-depleted incubation medium (D-series, $\delta \mathrm{D}_{\mathrm{H} 2 \mathrm{O}}=-200 \%$ o) and an accompanying experiment with medium without the D-depleted water $\left(\mathrm{N}\right.$-series, $\delta \mathrm{D}_{\mathrm{H} 2 \mathrm{O}}=$ $-55 \%$ ) yielded inconclusive results regarding the effect of $\delta \mathrm{D}$ values of medium water and the potential reversibility for AOM. Although results of York regression (Fig. 1e) yielded statistically different $\mathrm{D} / \mathrm{H}$ fractionations (116.5 \pm 3.5 vs. $141.1 \pm 6.0$ for $\mathrm{D}$ - and $\mathrm{N}$-series, respectively). The shallower slope for D-series is largely due to the last 

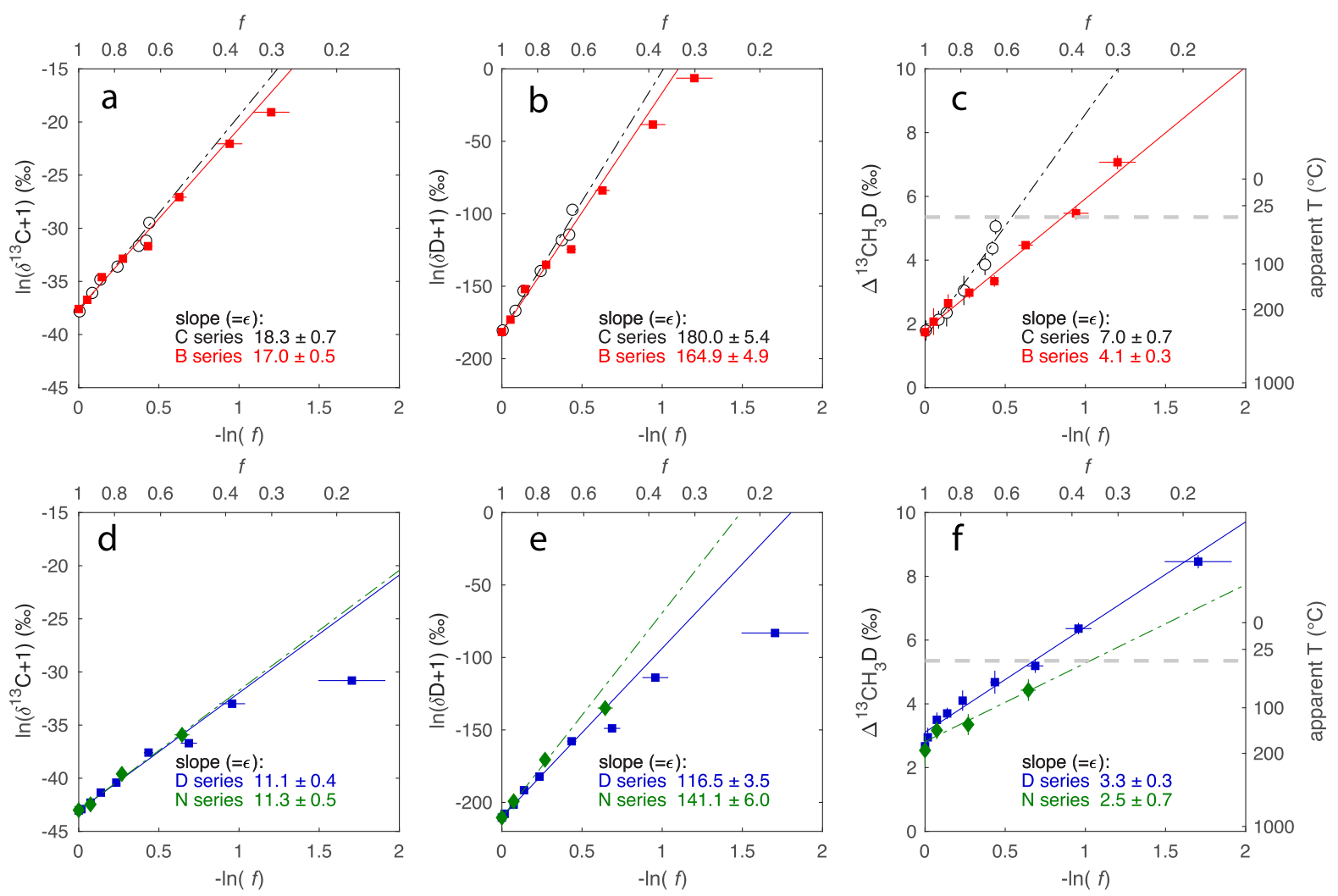

Fig. 1. Evolution of isotopologue compositions during methane consumption by AOM. Diagram (a), (b) and (c) show the results from C-and B-series (open circle and filled square, respectively), and diagrams (d), (e), and (f) show the results from D- and N-series (filled square and filled diamond, respectively). The slopes for least square fits are representing $\varepsilon$ values and shown in the diagram.

Table 2

Kinetic fractionation factors calculated from experimental results.

\begin{tabular}{lllll}
\hline Series & ${ }^{13} \varepsilon(\%)$ & ${ }^{2} \varepsilon(\%)$ & $\gamma$ & $1-\gamma(\%)$ \\
\hline C & $18.3 \pm 0.7$ & $180.0 \pm 5.4$ & $0.9872 \pm 0.0010$ & $12.8 \pm 1.0$ \\
B & $17.0 \pm 0.5$ & $164.9 \pm 4.9$ & $0.9916 \pm 0.0004$ & $8.4 \pm 0.4$ \\
D & $11.1 \pm 0.4$ & $116.5 \pm 3.5$ & $0.9947 \pm 0.0003$ & $5.3 \pm 0.3$ \\
N & $11.3 \pm 0.5$ & $141.1 \pm 6.0$ & $0.9952 \pm 0.0009$ & $4.8 \pm 0.9$ \\
\hline
\end{tabular}

Errors are estimated for uncertainty of $\mathrm{H}_{2} \mathrm{~S}$ measurements of $5 \%$ and $95 \%$ confidence interval for isotopologue measurements. Errors for $\gamma$ values are estimated by propagating errors for ${ }^{13} \alpha,{ }^{2} \alpha$ and the linear regression slope in $\ln (f)$ versus $\Delta^{13} \mathrm{CH}_{3} \mathrm{D}$ (Fig. 1) without considering covariance.

two data points, where methane consumption by AOM is above $50 \%$. Because the normal $\delta \mathrm{D}_{\mathrm{H} 2 \mathrm{O}}$ experiments $(\mathrm{N}-$ series) were not run above $47.5 \%$ methane consumption (Fig. 1e, Table 1), the comparison of D- and N-series remain inconclusive. During AOM, the $\delta \mathrm{D}$ values consistently increased from the initial value of $-190 \%$ up to $80 \%$ (Table 1). This is opposite from what is expected for isotope equilibration between methane and water. It would drive methane $\delta \mathrm{D}$ values lower towards equilibrium values, which are -360 and $-244 \%$ for $\mathrm{D}$ - and $\mathrm{N}$-series experiments, respectively. Accurate evaluation of the degree of reversibility requires the estimate of primary and secondary $\mathrm{D} / \mathrm{H}$ fractionation factors. We present a preliminary model in Appendix A, which suggests that reversibility could be as high as $60 \%$ during the activation of methane with methyl- coenzyme $\mathrm{M}$ reductase (MCR) for experiments $\mathrm{N}$ - and $\mathrm{D}$ series, whereas the same model predict reversibility as much as $69 \%$ for B- and C-series) (Fig. A2). Radiotracer $\left({ }^{14} \mathrm{C}\right.$ ) experiments with AOM cultures have demonstrated a substantial amount (up to $5 \%$ of net AOM rate) of carbon back flux from the DIC to methane (Holler et al., 2011b). Marlow et al. (2017) reported the rates of AOM estimated from the production of ${ }^{14} \mathrm{CO}_{2}$ from ${ }^{14} \mathrm{CH}_{4}$ and HDO from ${ }^{12} \mathrm{CH}_{3} \mathrm{D}$. They observed the rate based on HDO production is a factor of two faster than that based on ${ }^{14} \mathrm{CO}_{2}$, suggesting the back flux from MCR is $50 \%$ compared to the complete oxidation of $\mathrm{CH}_{4}$ to $\mathrm{CO}_{2}$ (Marlow et al., 2017). If deuterium isotope effect is considered, the back flux would be higher than $50 \%$, consistent with our estimate of $60 \%$ reversibility. Our focus is to present the data for ${ }^{13} \mathrm{CH}_{3} \mathrm{D}$ 


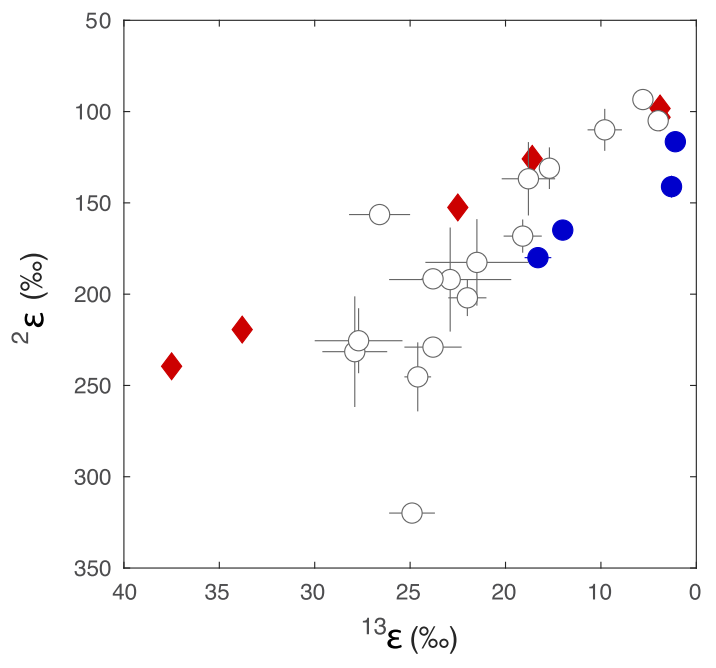

Fig. 2. Carbon and hydrogen isotope fractionations for aerobic and anaerobic microbial methane oxidation during laboratory culture experiments. Anaerobic oxidation of methane from this study and in psychrophilic AOM cultures from Holler et al. (2009) are shown in filled symbols (blue circles and red diamonds, respectively). They are compared with data for aerobic oxidation of methane shown in open symbols (data from Coleman et al., 1981, Kinnaman et al., 2007; Powelson et al., 2007; Wang et al., 2016).

such that the detailed investigation of the reversibility is the scope for future studies.

The values of $\Delta^{13} \mathrm{CH}_{3} \mathrm{D}$ of initial methane were $1.6 \%$ for $\mathrm{C}$ - and $\mathrm{B}$-series, and $2.5 \%$ for $\mathrm{D}$ - and $\mathrm{N}$-series. These values correspond to apparent clumped temperatures of 299 and $195^{\circ} \mathrm{C}$, respectively, suggesting a thermogenic origin. During the course of the experiments, the $\Delta^{13} \mathrm{CH}_{3} \mathrm{D}$ values of methane increased, and corresponding clumped temperature decreased towards experimental temperature of $37^{\circ}$ $\mathrm{C}$, reaching an apparent isotopologue equilibration. For two experiments that consumed $>70 \%$ of the supplied methane, however, $\Delta^{13} \mathrm{CH}_{3} \mathrm{D}$ values increased beyond that expected for equilibrium at $37^{\circ} \mathrm{C}\left(\Delta^{13} \mathrm{CH}_{3} \mathrm{D}_{\text {eq. }}=5.4 \%\right)$.
The highest $\Delta^{13} \mathrm{CH}_{3} \mathrm{D}$ value of $8.5 \%$ (Table 2) translates to a clumped temperature of $-46^{\circ} \mathrm{C}$. This is far below the incubation temperature of $37^{\circ} \mathrm{C}$ and clearly indicates predominantly kinetic fractionation of the clumped isotopologue, ${ }^{13} \mathrm{CH}_{3} \mathrm{D}$.

The increase of $\Delta^{13} \mathrm{CH}_{3} \mathrm{D}$ values of residual methane during oxidation is characteristic of AOM in our experiment. Fig. 3 compares the evolution of $\Delta^{13} \mathrm{CH}_{3} \mathrm{D}$ values observed during experiments for different methane oxidation processes. The value of $\Delta^{13} \mathrm{CH}_{3} \mathrm{D}$ for residual methane progressively decreased during methane oxidation by aerobic methanotrophic bacteria (Methylococcus capsulatus; Wang et al., 2016) as well as gas phase methane oxidations by $\mathrm{OH}$ and $\mathrm{Cl}$ radicals (Whitehill et al., 2017). Thus, although all three methane oxidation processes tested so far (AOM, aerobic methane oxidation, and gas phase oxidations) enriched the residual methane in ${ }^{13} \mathrm{C}$ and $\mathrm{D}$ containing isotopologues, AOM yielded a distinguishable trend in terms of clumped isotopologue signals (Fig. 3). This could be attributed to the reaction mechanism intrinsic to methane activation by MCR, as discussed in the next section.

\subsection{Transition state structure is linked to kinetic clumped isotopologue effects of $\mathrm{AOM}$}

Our experimental studies showed that methane oxidation by AOM increased the $\Delta^{13} \mathrm{CH}_{3} \mathrm{D}$ values of residual methane, in contrast to aerobic methanotrophy and gas phase oxidations, which decreased the $\Delta^{13} \mathrm{CH}_{3} \mathrm{D}$ values (Fig. 3). Following our definition of $\Delta^{13} \mathrm{CH}_{3} \mathrm{D}$ (Equation3 ), the slopes in $-\ln (f)$ vs. $\Delta^{13} \mathrm{CH}_{3} \mathrm{D}$ plots (Fig. 1c and 1f) are determined by all three isotopologue fractionation factors $\left({ }^{13,2} \alpha,{ }^{13} \alpha\right.$ and ${ }^{2} \alpha$; Equation-7). The calculated intrinsic clumped isotopologue fractionation factor $(\gamma$, Equation- 8$)$ for AOM ranges from 0.9872 to 0.9952 (Table 2). These $\gamma$ values are much less than unity compared to those measured for aerobic methanotrophy $(1.0004 \pm 0.0006$, Wang et al., 2016) and oxidation by $\mathrm{OH}$ and $\mathrm{Cl}$ radicals $(0.9997$ \pm 0.0012 and $0.9965 \pm 0.0007$, respectively) (Whitehill
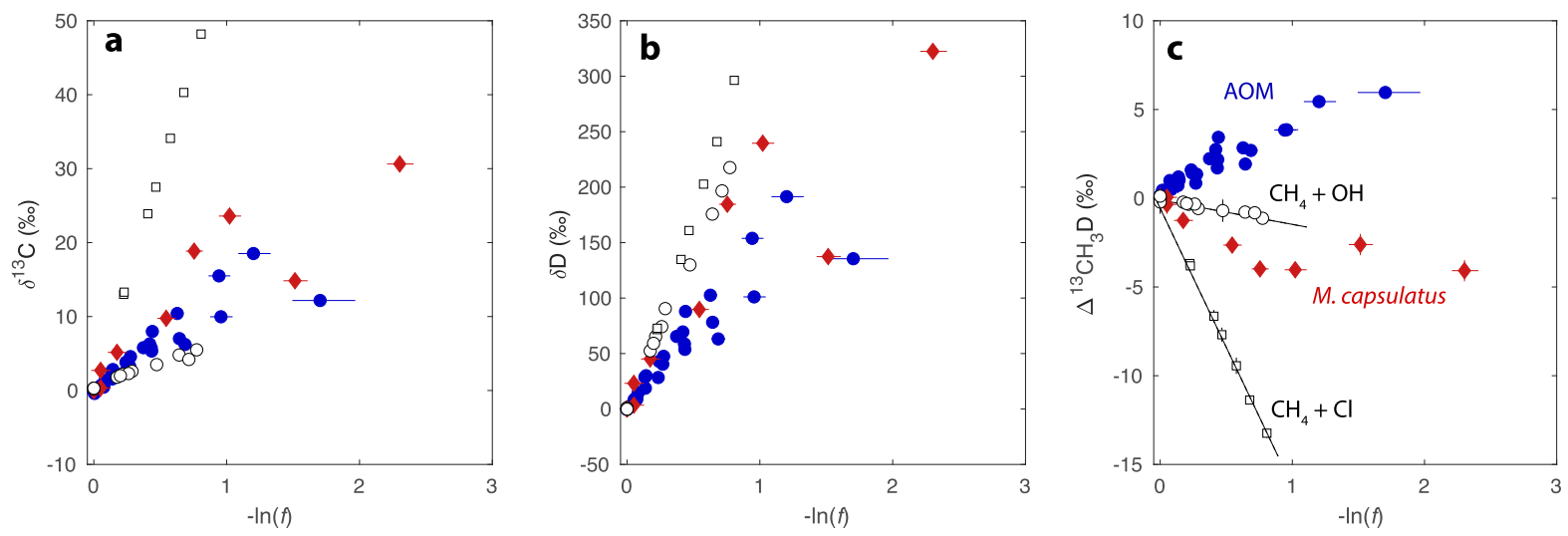

Fig. 3. Evolution of (a) $\delta{ }^{13} \mathrm{C}$, (b) $\delta \mathrm{D}$ and (c) $\Delta^{13} \mathrm{CH}_{3} \mathrm{D}$ values of residual methane during different methane oxidation processes. Methane oxidation by AOM (this study, filled blue circles), aerobic methane oxidation by M. capsulatus (Wang et al., 2016, filled red diamonds), and gas phase oxidation by $\mathrm{OH}$ and $\mathrm{Cl}$ radicals (Whitehill et al., 2017, open circles and squares, respectively) are shown. The values for $\delta^{13} \mathrm{C}, \delta \mathrm{D}$ and $\Delta{ }^{13} \mathrm{CH}_{3} \mathrm{D}$ are referenced against initial methane. 
et al., 2017). The different intrinsic $\gamma$ values could be related to the transition state structure of the reaction and, thus, characteristic to the enzyme that catalyzes the reaction of aerobic vs. anaerobic methanotrophy.

Clumped isotope effects, a fractionation that produces $\gamma<1$, can be thought of as double isotope effects. That is, a ${ }^{13} \mathrm{C}$ isotope effect on a $\mathrm{D}$ isotope effect, or a D isotope effect on a ${ }^{13} \mathrm{C}$ isotope effect. For methane molecules, the zero-point energy shift $(\triangle \mathrm{ZPE})$ for ${ }^{13} \mathrm{C} /{ }^{12} \mathrm{C}$ substitution in non-deuterated methane (i.e., ${ }^{13} \mathrm{CH}_{4}$ vs ${ }^{12} \mathrm{CH}_{4}$ ) is $29.8 \mathrm{~cm}^{-1}$. In comparison, $\triangle \mathrm{ZPE}$ for ${ }^{13} \mathrm{C} /{ }^{12} \mathrm{C}$ substitution in mono-deuterated methane (i.e., ${ }^{13} \mathrm{CH}_{3} \mathrm{D}$ vs ${ }^{12} \mathrm{CH}_{3} \mathrm{D}$ ) is $31.8 \mathrm{~cm}^{-1}$ (Fig. 4). The physical origin of preferential stability of ${ }^{13} \mathrm{CH}_{3} \mathrm{D}$ is the difference in these two $\triangle \mathrm{ZPE}$ values ( $\Delta \Delta \mathrm{ZPE}$ ) of $2.0 \mathrm{~cm}^{-1}$ (Fig. 4) (Whitehill et al., 2017). In the process of $\mathrm{C}-\mathrm{D}$ bond breakage (e.g., during methane oxidation), $\Delta \Delta \mathrm{ZPE}$ values change with the ${ }^{13} \mathrm{C}-\mathrm{D}$ stretching vibrational mode, resulting in the reduction of $\Delta \Delta \mathrm{ZPE}$ at the transition state, which leads to $\gamma<1$, and ${ }^{13} \mathrm{CH}_{3} \mathrm{D}$ reacts slower than the rate expected from the product rule (Whitehill et al., 2017). As D leaves from $\mathrm{CH}_{4}$ and the C$\mathrm{D}$ bond is stretched, $\triangle \triangle \mathrm{ZPE}$ decreases due to the longer bond length and lowered interaction between ${ }^{13} \mathrm{C}$ and $\mathrm{D}$ at the transition state, resulting in a smaller $\Delta \Delta \mathrm{ZPE}$ compared to that of the reactant $\mathrm{CH}_{4}$ (Fig. 4). Accordingly, little to negligible intrinsic clumped isotope effect is expected $(\gamma \simeq 1)$ for a reactant-like early transition state, where the initial $\triangle \triangle \mathrm{ZPE}$ is largely retained (Fig. 4c). In contrast, a large kinetic clumped isotope effect $(\gamma<1)$ is expected for product-like late transition state (Fig. 4b). Fig. 4 compares the transition state structures of the enzymes involved in AOM and aerobic methanotrophy, methyl coenzyme $\mathrm{M}$ reductase (MCR) and soluble methane monooxygenase (sMMO), respectively. Notably, the transition state for MCR has a relatively long $\mathrm{C}-\mathrm{H}$ bond length of $2.6 \AA$ and planar methyl-radical-like structure (Wongnate et al.,
2016), whereas sMMO has a shorter $(\sim 1.3 \AA) \mathrm{C}-\mathrm{H}$ bond length (Huang et al., 2013). The bond length difference between the two transition states is consistent with the observed clumped kinetic isotope effect.

The double isotope effect has been previously studied for enzyme kinetics using in vitro experiments and doublylabeled isotopologue substrates (Hermes et al., 1984; Scharschmidt et al., 1984; Rucker and Klinman, 1999). Scharschmidt et al. (1984) studied the carbon isotope effect during the oxidation of benzyl alcohol using a doublydeuterated substrate (benzyl alcohol-1,1- $d_{2}$ ). Similarly, Hermes et al. (1984) studied the double isotope effect of formate dehydrogenase using ${ }^{13} \mathrm{C}-\mathrm{D}$ doubly-labeled formate. They compared the carbon isotope effects for deuterated and non-deuterated reactants.

Fig. 5 compares the results of the above-mentioned enzyme assay studies on double isotope effect with those of our clumped methane measurements. Here, the carbon isotope fractionation factors for non-deuterated reactants $\left(k_{12} / k_{13}\right)_{\mathrm{H}}$ are compared to that of the deuterated counterpart $\left(k_{12} / k_{13}\right)_{\mathrm{D}}$. Note that the kinetic isotope fractionation factor is defined as ${ }^{12} \mathrm{C} /{ }^{13} \mathrm{C}$ (not ${ }^{13} \mathrm{C} /{ }^{12} \mathrm{C}$ as is commonly used in the geochemical community) to follow the convention in the enzyme community. The maximum clumped isotopologue fractionation is expected when $\Delta \Delta \mathrm{ZPE}=0 \mathrm{~cm}^{-1}$ at the transition state. Because the clumped isotope effect of ${ }^{13} \mathrm{C}-\mathrm{D}$ bond is $4-6 \%$ (Fig. 6), the maximum clumped isotopologue fractionation is 4-6\%o (i.e., $\left.\quad\left(k_{12} / k_{13}\right)_{\mathrm{D}} \simeq(1.004-1.006)_{\times}\left(k_{12} / k_{13}\right)_{\mathrm{H}}\right)$. This analysis does not consider tunneling effect that would produce additional non-canonical effects and further departure of $\gamma$ value from unity (e.g., Young et al., 2017). It can be seen that formate dehydrogenase reactions do not produce a clumped isotopologue effect $\left(\gamma \simeq 1\right.$, i.e., $\left(k_{12} / k_{13}\right)_{\mathrm{D}} \simeq$ $\left.\left(k_{12} / k_{13}\right)_{\mathrm{H}}\right)$, suggesting a reactant-like transition state. In contrast, the clumped effect $(\gamma<1)$ is fully expressed for

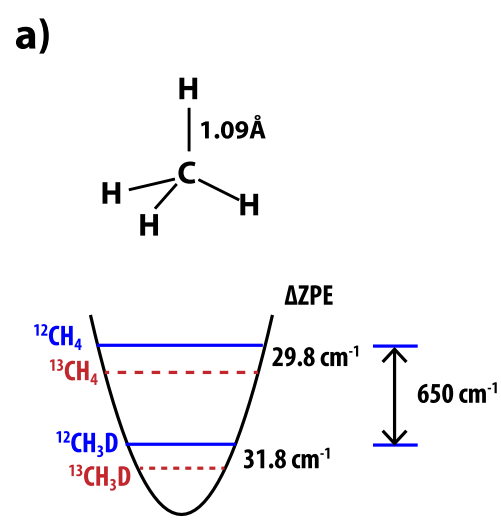

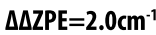

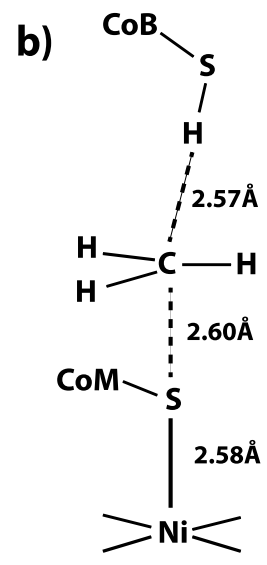

$\triangle \triangle \mathrm{ZPE} \approx 0 \mathrm{~cm}^{-1}$ c)

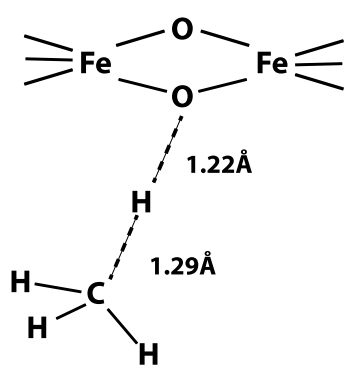

$\triangle \triangle \mathrm{ZPE} \approx 2.0 \mathrm{~cm}^{-1}$

Fig. 4. Illustration of $\Delta \Delta \mathrm{ZPE}$ effect as the origin of the clumped isotopologue effect. (a) shows that $\Delta \Delta \mathrm{ZPE}$ of $2 \mathrm{~cm}^{-1}$ is the difference in $\Delta \mathrm{ZPE}$ values between ${ }^{13} \mathrm{CH}_{4} /{ }^{12} \mathrm{CH}_{4}$ and ${ }^{13} \mathrm{CH}_{3} \mathrm{D} /{ }^{12} \mathrm{CH}_{3} \mathrm{D}$. The diagrams (b) and (c) show the geometry of transition states around methane activation sites for methyl-S-CoM reductase for AOM (from Wongnate et al., 2016) and sMMO for aerobic methane oxidation (from Huang et al., 2013). Due to the elongated $\mathrm{C}-\mathrm{H}$ bonds for methyl-S-CoM transition state, the $\Delta \Delta \mathrm{ZPE}$ effect is expected to be much smaller than $2 \mathrm{~cm}^{-1}$ at the transition state. 


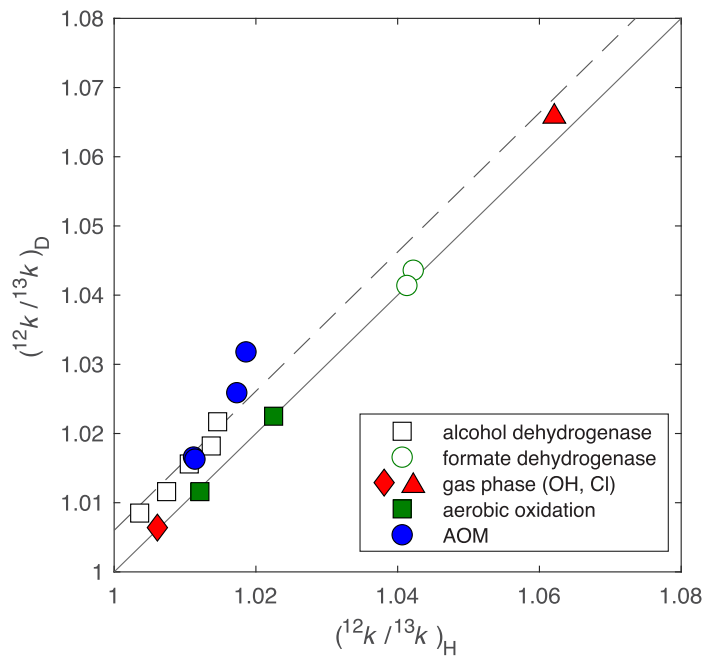

Fig. 5. Double isotope effect for $\mathrm{C}-\mathrm{H}$ bond breaking reactions. Here, carbon kinetic isotope effect $\left(k_{12} / k_{13}\right)$ is compared for nondeuterated versus deuterated compounds. Filled circles, AOM (this study); filled squares, aerobic methane oxidation (Wang et al., 2018); filled triangle and diamond, oxidation by $\mathrm{OH}$ and $\mathrm{Cl}$ radicals (Whitehill et al., 2017); open square, alcohol dehydrogenase (Scharschmidt et al., 1984); and open circle, formate dehydrogenase (Hermes et al., 1984). The solid line shows 1:1 relationship, which is expected when there is no intrinsic clumped effect. Dashed line shows 1:1.006 relationship, which is expected for clumped isotope effect of $6 \%$.

alcohol dehydrogenase, suggesting a product-like transition state. As a doubly-deuterated substrate is used for experiments by Scharschmidt et al. (1984), there could also be a secondary deuterium isotope effect (when D does not participate in bond breaking) for the alcohol dehydrogenase experiments. Similarly, there is a strong clumped isotope effect for AOM but no clumped effect for aerobic methane oxidation and gas phase oxidation by $\mathrm{OH}$ radicals, and a relatively small clumped effect for oxidation by $\mathrm{Cl}$ radicals (Fig. 5).

\subsection{Clumped isotopologues as tracer of methane oxidation processes}

\subsubsection{Methane isotopologue compositions as a result of kinetic fractionations}

Major sinks of methane in the environment include atmospheric oxidation by $\mathrm{OH}$ and $\mathrm{Cl}$ radicals, and the aerobic and anaerobic microbial oxidation of methane. If these reactions impart characteristic isotope fractionation signals, the resulting methane isotope ratios can be used to partition these processes (Haghnegahdar et al., 2017; Whitehill et al., 2017). For example, ${ }^{2} \alpha /{ }^{13} \alpha$ ratio for gas phase oxidation by $\mathrm{OH}$ radicals is $\sim 58$, which is distinctively different from the ratio for aerobic microbial oxidation of methane between 6 and 15 (e.g., Whiticar and Schaefer, 2007; Wang et al., 2016). Thus, $\delta^{13} \mathrm{C}$ and $\delta \mathrm{D}$ values of methane can be used to decouple gas phase versus microbial oxidation processes (e.g., Kai et al., 2011; Rigby et al., 2012). Experimentally measured $\left.{ }^{2} \alpha\right|^{13} \alpha$ ratios

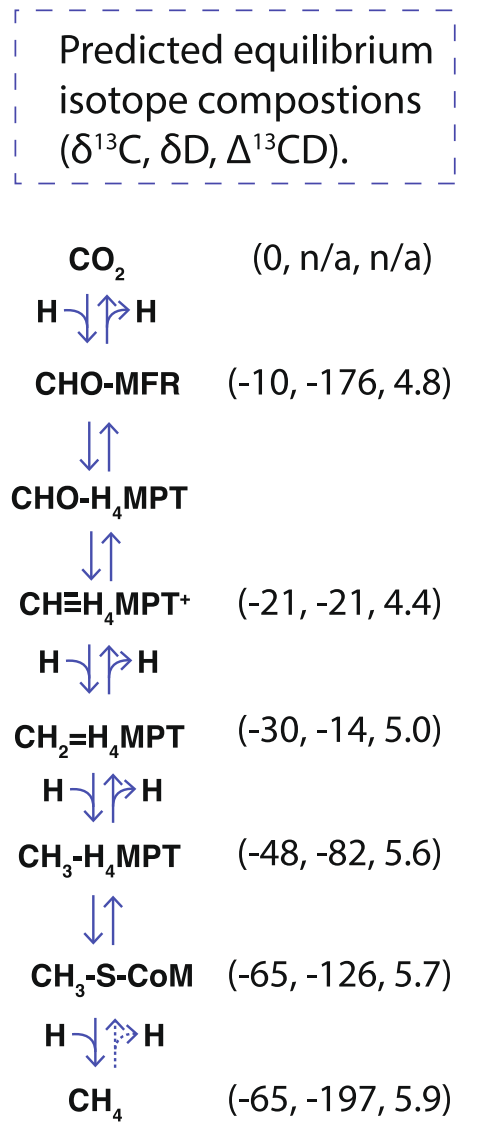

Fig. 6. A schematic showing the pathway of hydrogenotrophic methanogenesis and approximate equilibrium isotope and isotopologue fractionations estimated from truncated molecular simulation (Wang et al., 2015). Predicted isotope compositions, $\delta^{13} \mathrm{C}$ and $\delta \mathrm{D}$ (in \%o), are referenced to those of $\mathrm{CO}_{2}$ and $\mathrm{H}_{2} \mathrm{O}$, respectively, and $\Delta^{13} \mathrm{CD}$ value is against stochastic distributions. Pathway is taken from Thauer (2011). Abbreviations are: MFR, methanofuran; $\mathrm{H}_{4} \mathrm{MPT}$, tetrahydromethanopterin; CoM, coenzyme $\mathrm{M}$. The last reaction, reduction of methyl-S-CoM to methane is exergonic and often unidirectional, and is hypothesized to be the source of kinetic D- and ${ }^{13} \mathrm{CH}_{3} \mathrm{D}$-isotope signals of microbial methane.

for AOM and aerobic methane oxidation, however, overlap, showing that these ratios may not be able to distinguish aerobic versus anaerobic methanotrophy (Fig. 2). Our experiments demonstrate that $\mathrm{AOM}$ produces distinct $\Delta^{13} \mathrm{CH}_{3} \mathrm{D}$ (and likely $\Delta^{12} \mathrm{CH}_{2} \mathrm{D}_{2}$ ) trajectories that are very different from aerobic methane oxidation and gas phase oxidation of methane (Fig. 3).

What is the range of isotopologue compositions of methane in nature when methane is produced by methanogens and consumed by AOM? Below we show that the wide range of isotopologue compositions of methane are expected from available experimental data for methanogens (Stolper et al, 2015; Young et al., 2017; Gruen et al., 2018) and AOM (this study). The relatively narrow range of observed $\delta^{13} \mathrm{C}, \delta \mathrm{D}$, and $\Delta^{13} \mathrm{CH}_{3} \mathrm{D}$ values of methane in marine environment (where AOM occurs) suggests the importance of equilibrium fractionation, as opposed to two kinetic fractionations. 
In the simplest case, when the rate of methane production equals consumption by AOM (i.e., at a steady state), the isotopologue composition of methane is determined by the ratio of isotope fractionations by methanogenesis $\left(\alpha_{\mathrm{mtg}}\right)$ and $\operatorname{AOM}\left(\alpha_{\mathrm{AOM}}\right)$.

$\delta^{13} \mathrm{C}_{\mathrm{CH} 4}=\frac{{ }^{13} \alpha_{m t g}}{{ }^{13} \alpha_{A O M}}\left(\delta^{13} \mathrm{C}_{\mathrm{CO} 2}+1\right)-1, \quad$ and

$\delta \mathrm{D}_{\mathrm{CH} 4}=\frac{{ }^{2} \alpha_{m t g}}{{ }^{2} \alpha_{A O M}}\left(\delta \mathrm{D}_{\mathrm{H} 2 \mathrm{O}}+1\right)-1$.

Using a typical range of ${ }^{13} \alpha_{\mathrm{mtg}}$ values of $0.97-0.92$ for laboratory cultures of hydrogenotrophic methanogens (e.g., Botz et al., 1996; Okumura et al., 2016) and ${ }^{13} \alpha_{\text {AOM }}$ of 0.97-0.99 (Table 2 and Holler et al., 2009), steady state $\delta^{13} \mathrm{C}_{\mathrm{CH} 4}$ ranges from 0 to $-70 \%$ relative to $\delta^{13} \mathrm{C}_{\mathrm{CO} 2}$. The higher end is comparable to methane equilibrated at near ambient temperatures (Fig. 6). Similarly, a typical ${ }^{2} \alpha_{\mathrm{mtg}}$ value of $0.73-0.66$ (low $\mathrm{pH}_{2}$ experiments by Okumura et al., 2016), and ${ }^{2} \alpha_{\text {AOM }}$ values from 0.76 to 0.90 (Table 2 and Holler et al., 2009) yield $\delta \mathrm{D}_{\mathrm{CH} 4}$ of -40 to $-270 \%$ relative to $\delta \mathrm{D}_{\mathrm{H} 2 \mathrm{O}}$. This range encompasses the observed value of $\delta \mathrm{D}=-200$ to $-150 \%$ o for methane in marine environment (e.g., Whiticar, 1999, Okumura et al., 2016).

The value of $\Delta^{13} \mathrm{CH}_{3} \mathrm{D}$ of methane under a steady state is simply:

$\Delta^{13} \mathrm{CH}_{3} \mathrm{D}=\ln \left(\gamma_{m t g}\right)-\ln \left(\gamma_{A O M}\right)$

The $\ln \left(\gamma_{\text {AOM }}\right)$ values from this study $(-4.8$ to $-12.8 \%$, Table 2) and experimentally derived $\ln \left(\gamma_{\mathrm{mtg}}\right)$ values of -3.8 to $+2.3 \%$ for hydrogenotrophic methanogenesis (Gruen et al., 2018; Douglas et al., 2020) yield the range of the $\Delta^{13} \mathrm{CH}_{3} \mathrm{D}$ value from +1.0 to $+15.1 \%$. Most environmental data show $\Delta^{13} \mathrm{CH}_{3} \mathrm{D}$ values smaller than ca. $7 \%$, corresponding to apparent equilibrium temperatures of ca. $-12{ }^{\circ} \mathrm{C}$ (e.g., Stolper et al., 2015; Wang et al., 2015; Douglas et al., 2017). The values of $\Delta^{13} \mathrm{CH}_{3} \mathrm{D}$ higher than $7 \%$ are uncommon but can be interpreted as a result of mixing (Douglas et al., 2017). Since mixing is non-linear for $\Delta^{13} \mathrm{CH}_{3} \mathrm{D}$, mixing of two pools of methane with different $\delta^{13} \mathrm{C}$ and $\delta \mathrm{D}$ values can produce methane with a $\Delta^{13} \mathrm{CH}_{3} \mathrm{D}$ value that is outside of the two $\Delta^{13} \mathrm{CH}_{3} \mathrm{D}$ values of original methane. The observed relatively narrow range of $\Delta^{13} \mathrm{CH}_{3} \mathrm{D}$ values, therefore, argues for the importance of equilibrium, as opposed to kinetic fractionation for methane in marine environments.

\subsubsection{Methane isotopologue compositions as a result of equilibrium fractionations}

Recent studies linked near-equilibrium clumped isotopologue signals (both $\Delta^{13} \mathrm{CH}_{3} \mathrm{D}$ and $\Delta^{12} \mathrm{CH}_{2} \mathrm{D}_{2}$ ) of methane in shallow marine sediment porewater (Ash et al., 2019) and deep fracture fluids to AOM (Giunta et al., 2019). For the Baltic Sea site, Ash et al. (2019) observed kinetic $\Delta{ }^{13} \mathrm{CH}_{3} \mathrm{D}$ and $\Delta \mathrm{CH}_{2} \mathrm{D}_{2}$ values (i.e., lower than expected for equilibrium) in shallow $<20 \mathrm{~m}$ sediments. Both $\Delta{ }^{13} \mathrm{CH}_{3} \mathrm{D}$ and $\Delta \mathrm{CH}_{2} \mathrm{D}_{2}$ values increased with depth where AOM is expected. This is consistent with our results that AOM increased the $\Delta^{13} \mathrm{CH}_{3} \mathrm{D}$ value. The environmental study of Ash et al. (2019), however, is not conclusive about equilibrium vs. kinetic control for the observed isotope effects. This is because if we had stopped our experiments at $\mathrm{f}>0.5$, then we would not be able to demonstrate if our data resulted from equilibrium or kinetic isotope effects. Similarly, it is uncertain whether $\Delta^{13} \mathrm{CH}_{3} \mathrm{D}$ values exceeding those of equilibration would appear deeper in the sediment studied by Ash et al. (2019). Such a signal would indicate kinetic isotopologue fractionations.

The estimated rate of AOM for Baltic Sea site studied by Ash et al. 2019 (0.84 pmol $\mathrm{CH}_{4} \mathrm{~cm}^{-3}$ day $^{-1}$, Dijkstra et al., 2018 ) is at the low end for marine subsurface sulfate methane transition zone (Sivan et al., 2007; Knittel and Boetius, 2009) and appears under low sulfate concentrations $(<1 \mathrm{mM})$, which strongly influence the isotope effects of AOM (Yoshinaga et al., 2014). In comparison, the rate for our AOM culture is much faster (about $150 \mathrm{nmol} \mathrm{cm}^{-3}$ medium day $^{-1}$ ). A faster rate of AOM at high sulfate concentrations and therefore higher thermodynamic drive likely contributed kinetic signals observed in this study. While the results of this study demonstrate that AOM does not always produce near-equilibrium signals, it remains to be tested if and under what conditions AOM (and methanogenesis) produces equilibrium signals.

Here, we consider methane isotopologue fractionation in nature, in particular that found in marine environment, as a result of equilibrium fractionation by reversible enzymatic processes. Hydrogenotrophic methanogenesis is a seven-step reaction involving the transfer of eight electrons (Fig. 6). ANME carry most enzymes involved in methanogenesis, and is thought to carry out the reverse reaction of methanogenesis (e.g., Hallam et al., 2004). The last step of methanogenesis, the reduction of methyl-S-CoM, is catalyzed by MCR:

$$
\mathrm{CH}_{3}-\mathrm{S}-\mathrm{CoM}+\mathrm{HS}-\mathrm{CoB} \leftrightarrow \mathrm{CH}_{4}+\mathrm{CoM}-\mathrm{S}-\mathrm{S}-\mathrm{CoB}
$$

where $\mathrm{CoB}$ and $\mathrm{CoM}-\mathrm{S}-\mathrm{S}-\mathrm{CoB}$ are coenzyme $\mathrm{B}$ and heterodisulfide complex, respectively. The reverse reaction is the first step for AOM. For methanogenesis, the reaction is exergonic at physiological concentrations so that the reaction is favored toward the product methane (e.g., Scheller et al., 2010, 2013; Thauer, 2011). The first step of methanogenesis, the reduction of $\mathrm{CO}_{2}$ to formyl-MFR, in contrast, is highly endergonic, and requires a potential as low as $-500 \mathrm{mV} \mathrm{Eh}$, which is much lower than the potential set by the $\mathrm{H}_{2} / \mathrm{H}^{+}\left(-400 \mathrm{mV}\right.$ Eh at 1 bar $\mathrm{pH}_{2}$ at $\mathrm{pH}=7$, which is a rare condition) (Thauer et al., 2008). One way of achieving this low redox potential is by coupling the highly exergonic last step of methanogenesis (equation-12) to the endergonic $\mathrm{CO}_{2}$ activation step in a so-called electron bifurcation reaction (Thauer et al., 2010; Kaster et al., 2011).

The exergonic nature of the last step of methanogenesis can explain kinetic $\delta \mathrm{D}$ and $\Delta{ }^{13} \mathrm{CH}_{3} \mathrm{D}$ isotope fractionations observed in methanogen culture experiments, which are often carried out at high $\mathrm{pH}_{2}\left(>1\right.$ bar $\left.\mathrm{pH}_{2}\right)$ (Valentine et al., 2004; Okumura et al., 2016; Gruen et al., 2018). Fig. 6 shows equilibrium ${ }^{13} \mathrm{C} /{ }^{12} \mathrm{C}, \mathrm{D} / \mathrm{H}$ and ${ }^{13} \mathrm{C}-\mathrm{D}$ isotope compositions estimated from $a b$ initio calculations (for details see Appendix B). If the addition of the third-H, reduction of $\mathrm{CH}_{2}=\mathrm{H}_{4} \mathrm{MPT}$ (methylene tetrahy- 
dromethanopterin) to $\mathrm{CH}_{3}-\mathrm{H}_{4} \mathrm{MPT}$, is reversible (as suggested by Stolper et al., 2015), methyl-H of methyl-SCoM would be isotopically equilibrated with water and result in $\delta \mathrm{D}=-126 \%$ ( when $\delta \mathrm{D}_{\mathrm{H} 2 \mathrm{O}}=0 \%$ ). The fourth (i.e., the last) $\mathrm{H}$ addition is exergonic and produces a large kinetic isotope effect under most physiological conditions. The resulting $\delta \mathrm{D}$ value of methane can be derived as:

$\delta \mathrm{D}_{\mathrm{CH} 4}=3 / 4 \cdot{ }^{2} \alpha_{\mathrm{S}}\left(\delta \mathrm{D}_{\mathrm{CH} 3}+1\right)+1 / 4 \cdot{ }^{2} \alpha_{\mathrm{p}}\left(\delta \mathrm{D}_{\mathrm{H} 2 \mathrm{O}}+1\right)-1=-374 \% o$

where ${ }^{2} \alpha_{S}$ and ${ }^{2} \alpha_{p}$ are secondary and primary kinetic isotope fractionation factors, respectively (Wang et al., 2015; Gruen et al., 2018). We use ${ }^{2} \alpha_{p}$ of 0.3 and ${ }^{2} \alpha_{S}$ of 0.84 from Scheller et al. (2013). This simple analysis shows that kinetic $\delta \mathrm{D}$ value of $-374 \%$ is due to three moderately Ddepleted $\mathrm{H}$ atoms from methyl-CoM of $-266 \%$ with one highly D-depleted $(-700 \%) \mathrm{H}$ added during the last step of methanogenesis. The value of $-374 \%$ is within the range (-300 to $-400 \%$ ) commonly observed for laboratory cultures of methanogens (Valentine et al., 2004; Okumura et al., 2016). For clumped isotopologues, the last step of methanogenesis was also proposed to be responsible for low and kinetic $\Delta^{13} \mathrm{CH}_{3} \mathrm{D}$ (and $\delta \mathrm{D}$ ) values (Stolper et al., 2015; Gruen et al., 2018). One study showed that kinetic $\Delta^{13} \mathrm{CH}_{3} \mathrm{D}$ values are not specific to the metabolic pathways of methanogenesis (e.g., acetoclastic vs. hydrogenotrophic), suggesting that they are produced during enzymatic reactions common in all methanogenic pathways, such as the reduction of methyl-CoM (Gruen et al., 2018). Another study, however, measured different isotopologue signals in ${ }^{13} \mathrm{CH}_{3} \mathrm{D}$ and ${ }^{12} \mathrm{CH}_{2} \mathrm{D}_{2}$ for different pathways of methanogenesis (Young et al., 2017). The different observations could be related to the source of methyl group substrates. Thus, the question remains open regarding the significance of pathways in determining the methane isotopologue compositions.

The reverse of reaction (12) is the first step of AOM, and limits the rate of AOM because, under usual physiological conditions, the reaction is favored towards methane production (e.g., Thauer, 2011). It has been shown that ANME contain high concentrations of MCR to increase the rate of reaction (Shima and Thauer, 2005; Heller et al., 2008). When the reaction (12) in AOM is rate limiting and reversible, it would lead to $\mathrm{D} / \mathrm{H}$ isotope as well as ${ }^{13} \mathrm{CH}_{3} \mathrm{D}$ isotopologue equilibria. Here, the last $\mathrm{H}$ in methane is derived from HS-coenzyme $\mathrm{B}$, whose $\mathrm{H}$ isotope ratio is likely to be equilibrated with water because of a generally weak S-H bonds. Therefore, there is a good reason to suspect that AOM will drive the isotopologue signals of the remaining methane towards equilibrium of $\delta \mathrm{D} \simeq-197 \%$ and $\Delta^{13} \mathrm{CH}_{3} \mathrm{D} \simeq 5.9 \%$ (at ambient temperatures) when the first step of AOM is highly reversible (Fig. 6). The kinetic Dand ${ }^{13} \mathrm{CH}_{3} \mathrm{D}$ signals observed in this study suggest that the first step of AOM was not fully reversible under our experimental conditions. It is possible that reversibility of AOM is linked to sulfate concentrations so that experiments with low sulfate concentrations may produce equilibrium $\Delta^{13} \mathrm{CH}_{3} \mathrm{D}$ values. This, however, remains to be experimentally verified.
Using ${ }^{14} \mathrm{C}$ spiked methane, Holler et al. (2011b) measured the reversibility of AOM cultures between 5 and $13 \%$. The reversibility measured by ${ }^{14} \mathrm{C}$ represents the reversibility of the entire reactions from $\mathrm{CO}_{2}$ and $\mathrm{CH}_{4}$ during AOM. In contrast, equilibrium $\delta \mathrm{D}$ and $\Delta^{13} \mathrm{CH}_{3} \mathrm{D}$ values can be achieved by the reversibility of only the first step of AOM. Although our results for D- and N-series experiments are preliminary, $60 \%$ reversibility of the first step of AOM is possible. The reversibility of this first step of AOM should be tested in future experiments.

\section{CONCLUSIONS}

Fractionations of methane isotopologues during the anaerobic oxidation of methane (AOM) were investigated experimentally with sediment-free cultures of ANME-1 archaea and partner bacteria. The AOM in our experiments produced kinetic isotope fractionations of 11.1-18.3\%o and $117-180 \%$ of ${ }^{13} \mathrm{C}$ and $\mathrm{D}$, respectively, where residual methane is enriched in ${ }^{13} \mathrm{C}$ and $\mathrm{D}$ relative to ${ }^{12} \mathrm{C}$ and ${ }^{1} \mathrm{H}$. The clumped isotopologue, ${ }^{13} \mathrm{CH}_{3} \mathrm{D}$, also followed kinetic fractionation, where $\Delta^{13} \mathrm{CH}_{3} \mathrm{D}$ values increased up to $8.4 \%$, which is above the value expected for isotopologue equilibrium. Experiments to test the effect of $\delta \mathrm{D}$ values of medium water were inconclusive about the reversibility of AOM. Previous laboratory culture experiments of methanogenic microbes have exclusively produced lower $\Delta^{13} \mathrm{CH}_{3} \mathrm{D}$ signals than those expected for equilibrium at their growth temperatures. Our results demonstrate that AOM increases the $\Delta^{13} \mathrm{CH}_{3} \mathrm{D}$ value and produces low apparent temperature signals for remaining methane, and can explain the range of $\Delta^{13} \mathrm{CH}_{3} \mathrm{D}$ values measured for methane in natural environments.

\section{Declaration of Competing Interest}

The authors declare that they have no known competing financial interests or personal relationships that could have appeared to influence the work reported in this paper.

\section{ACKNOWLEDGEMENTS}

We thank associate editor, Ann Pearson, and three anonymous reviewers for constructive comments that significantly improved the manuscript, and Susanne Menger and Martina Alisch for the assistance in cultivation, in experiments and geochemical measurements. This work was supported by the NASA Astrobiology Institute "Rock-Powered Life" project under cooperative agreement NNA15BB02A, NSF-Geobiology and Low Temperature Geochemistry, EAR-1852946, N. Braunsdorf and D. Smit of Shell PTI/EG, and the Deep Carbon Observatory (to S.O.). J.H.R. was also supported by the Grayce B. Kerr Fellowship, the Robert R. Shrock Fellowship and the Callahan Dee Fellowship at MIT. D. S.G. was supported by a National Science Foundation Graduate Research Fellowship, the Neil and Anna Rasmussen Foundation Fund, the Grayce B. Kerr Fellowship, and a Shell-MIT Energy Initiative Graduate Fellowship. G. W. was supported by the DFG cluster of Excellence EXC 2077 'The Ocean Floor - Earth's Uncharted Interface' at MARUM, University Bremen and the Max Planck Society. 


\section{APPENDIX A. A MODIFIED RAYLEIGH EQUATION THAT INCLUDES A REVERSIBLE REACTION}

The potential effect of reversibility for the derived fractionation factor $(\alpha)$ and the $\delta \mathrm{D}$ value of medium water was evaluated by constructing a modified Rayleigh fractionation model that includes internal reversibility during the first step of AOM, as the scheme shown in Fig. A1. The model does not track the reaction beyond $\mathrm{CH}_{3}-\mathrm{S}$ $\mathrm{CoM}$ due to uncertain isotope fractionation factors for subsequent reactions. Although incomplete, this model approach enables reasonable complexity and reduces the number of unknown variables.

Continuity equations for the reaction scheme in Fig. A1 can be written as:

$\frac{d x_{1}}{d t}=-k_{1} x_{1}+k_{2} y_{1}$

$\frac{d y_{1}}{d t}=k_{1} x_{1}-\left(k_{2}+k_{3}\right) y_{1}$

$\frac{d x_{2}}{d t}=-\left(\frac{1}{4} \alpha_{1 p}+\frac{3}{4} \alpha_{1 s}\right) k_{1} x_{2}+\alpha_{2 p} k_{2} d_{H} y_{1}+\alpha_{2 s} k_{2} y_{2}$

$\frac{d y_{2}}{d t}=-\frac{3}{4} \alpha_{1 s} k_{1} x_{2}+\left[\alpha_{2 s} k_{2}+\left(\frac{1}{3} \alpha_{3 p}+\frac{2}{3} \alpha_{3 s}\right) k_{3}\right] y_{2}$

where, $x_{1}, x_{2}, y_{1}$, and $y_{2}$ are concentrations for $\mathrm{CH}_{4}, \mathrm{CH}_{3} \mathrm{D}$, $\mathrm{CH}_{3}$-S-CoM and $\mathrm{CH}_{2} \mathrm{D}-\mathrm{S}-\mathrm{CoM}$, respectively, and $k_{n}$ $(\mathrm{n}=1,2$, or 3$)$ are the first order rate constants for nondeuterated isotopologues, and $\alpha_{\mathrm{np}}$ and $\alpha_{\mathrm{ns}}$ are the primary and secondary isotope fractionation factors, corresponding

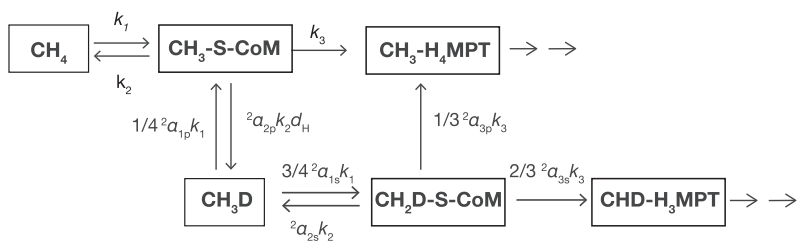

Fig. A1. The reaction scheme used to derive the modified Rayleigh equation that includes the reversibility of the first step. See text for symbols. to the rate constant, $k_{n}$. For natural $\mathrm{D}$ abundance, the flux from $\mathrm{CH}_{3} \mathrm{D}$ to $\mathrm{CH}_{4}$ is ignored for the mass-balance of $\mathrm{CH}_{3}$ S-CoM. This simplifies the Eq. A(2) and subsequent solutions without affecting the results.

Assuming steady states for intermediate species (i.e., $d y_{1} /$ $\left.d t=d y_{2} / d t=0\right)$, differential Eqs. (A1)-(A4) can be reduced to:

$\frac{d x_{1}}{d t}=a x_{1}$

$\frac{d x_{2}}{d t}=b x_{1}+c x_{2}$

where,

$a=-k_{1} \phi$

$b=\alpha_{2 p} d_{H} k_{1}(1-\phi)$

$c=-k_{1}\left[\left(\frac{1}{4} \alpha_{1 p}+\frac{3}{4} \alpha_{1 s}\right)+\frac{3}{4} \frac{\alpha_{1 s} \alpha_{2 s}(1-\phi)}{\alpha_{2 s}(1-\phi)+\left(\frac{1}{3} \alpha_{3 p}+\frac{2}{3} \alpha_{3 s}\right) \phi}\right] x_{2}$

and $\phi$ is the forward commitment defined as (e.g. Singh et al., 2016):

$\phi=\frac{k_{3}}{k_{2}+k_{3}}$

The value of $\phi$ varies from 1 to 0 for unidirectional to fully reversible reactions, respectively. This parameterization avoids the value of $\phi$ becoming infinity (as opposed to defining $\phi=k_{2} / k_{3}$ ). The analytical solutions for the differential Eqs. (A5) and (A6) are:

$x_{1}(t)=x_{1}^{i} e^{a t}$

$x_{2}(t)=x_{1}^{i} \frac{b}{a-c} e^{a t}+\left(x_{2}^{i}-x_{1}^{i} \frac{b}{a-c}\right) e^{c t}$

where, $x_{1}{ }^{i}$ and $x_{2}{ }^{i}$ are initial concentrations. Eqs. (A11) and (A12) are used to derive an analytical solution for the $\delta D$ value of methane as a function of fraction remaining, $f$ $(=\exp (a t))$ :

$\delta D+1=\frac{\omega}{R_{i}}+\left(1-\frac{\omega}{R_{i}}\right) f^{\theta-1}$
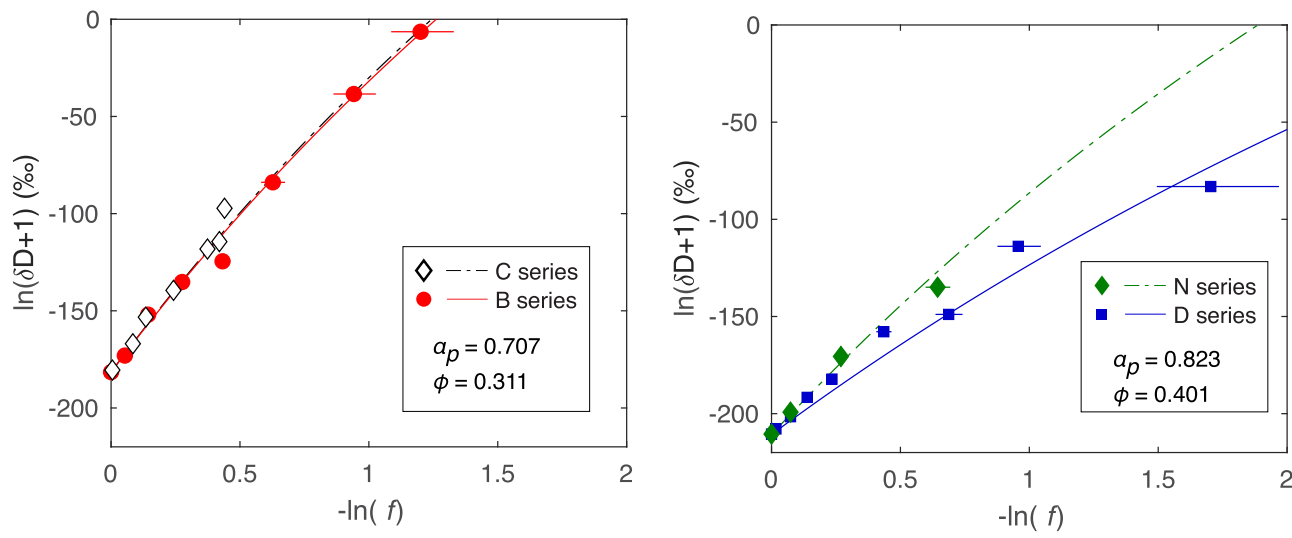

Fig. A2. Model fit to the data for four experiments. The best fit was obtained for primary D/H fractionation factor $\left(\alpha_{1 \mathrm{p}}\right)$ of 0.707 and forward commitment $(\phi)$ of 0.311 for B- and C-series experiments, and 0.823 and 0.401 , respectively for D- and $\mathrm{N}$-series experiments. 
where $\omega=b /(a-c)$ and $\theta=c / a$ (in Eqs. (A7)-(A9)), and $R_{i}$ is the isotopologue ratio $\left(\mathrm{CH}_{3} \mathrm{D} / \mathrm{CH}_{4}\right)$ at $t=0$. Note that the ratio is four times that of bulk $\mathrm{D} / \mathrm{H}$ ratio of methane because of the symmetric factors. Eq. (A13) compares the analytical solution for the reaction scheme in Fig. A1 with that of the conventional Rayleigh equation.

We applied the Eq. (A13) to fit $\delta \mathrm{D}$ data for D- and Nseries experiments to examine the potential impact of $\delta \mathrm{D}$ values of medium water. We assumed the secondary isotope effects $\left(\alpha_{1 \mathrm{~s}}, \alpha_{2 \mathrm{~s}}\right.$, and $\left.\alpha_{3 \mathrm{~s}}\right)$ of 0.85 (following Scheller et al., 2013 ), and fit the data with two fitting parameters, $\alpha_{1 \mathrm{p}}$ (assumed equal to $\alpha_{3 p}$ ), and $\phi$. The value of $\alpha_{2 p}$ was constrained by $\alpha_{1 \mathrm{p}}$ and the equilibrium fractionation between $\mathrm{CH}_{4}$ and $\mathrm{CH}_{3}-\mathrm{S}-\mathrm{CoM}$ in Fig. 6. The MATLAB script of the model is available in Electronic Annex. The best fit to the data was obtained for $\alpha_{1 p}=\alpha_{3 p}=0.823$ and $\phi=0.40$ (Fig. A1), suggesting a potentially substantial reversibility for the reaction (i.e., back flux is $60 \%$ of the forward flux). This model, however, is highly preliminary because of the lack of data for control experiments ( $\mathrm{N}$-series) at later time points of the experiments $(f<0.5$, Fig. 1e). We recognize that this is important area of future research, and we present this model in order to aid the design of future experiments. We suggest that the best approach would use water with more distinct $\delta \mathrm{D}$ values by spiking with $\mathrm{D}_{2} \mathrm{O}$ and taking data for later time steps, where the effect of reversibility is better expressed than in earlier time steps.

\section{APPENDIX B. ESTIMATION OF EQUILIBRIUM FRACTIONATIONS}

Equilibrium fractionations shown in Fig. 6 were estimated by calculating reduced partition function ratios following the conventional formula (e.g., Bigeleisen and Mayer, 1947; Urey, 1947). Normal mode frequencies were estimated by molecular simulation by B3LYP with the 6-311 $+\mathrm{G}^{* *}$ basis set using GAMESS software (Gordon and Schmidt, 2005). Reduced partition function ratios for intermediate compounds were approximated by simple molecules, in which the same number of $\mathrm{H}, \mathrm{N}, \mathrm{O}$, and $\mathrm{S}-$ atoms are bound to the $\mathrm{C}$ atom that contains the $\mathrm{C}-\mathrm{H}$ bonds in question. We used following compounds as analogues: formamide (for CHO-MFR in Fig. 6), pyrimidine (for $\mathrm{CH}=\mathrm{H}_{4} \mathrm{MPT}$ ), methylenediamine (for $\mathrm{CH}_{2}=$ $\mathrm{H}_{4} \mathrm{MPT}$ ), methylamine (for $\mathrm{CH}_{3}-\mathrm{H}_{4} \mathrm{MPT}$ ), and methanethiol (for $\mathrm{CH}_{3}-\mathrm{S}-\mathrm{CoM}$ ). Discussion for the accuracy for using these "cutoff" model can be found in Heskey and Schowen (1983) and Rucker and Klinman (1999). The results of the calculation should be taken as a first order approximation because of a number of assumptions made. In addition to the use of cutoff molecules, our calculation assumed gas phase molecules and harmonic oscillators. For $\mathrm{D} / \mathrm{H}$ isotope fractionation, in particular, anharmonic effect and solvation are expected to be important (Richet et al., 1977; Wang et al., 2009). These effects, however, tend to cancel out when comparing fractionation factors estimated by the same computational method such that relative fractionation factors among modeled compounds can be accurate (Wang et al., 2009). We used the experimental fractionation factor for $\mathrm{H}_{2} \mathrm{O}($ gas $) / \mathrm{H}_{2} \mathrm{O}$ (liquid) of Horita and Wesolowski (1994) and calculated the fractionation factor for $\mathrm{C}-\mathrm{H}$ compounds against $\mathrm{H}_{2} \mathrm{O}$ (gas) to derive the equilibrium fractionation factor against liquid $\mathrm{H}_{2} \mathrm{O}$. For clumped isotope effect, anharmonic effects can produce about $0.3 \%$ bias for $\Delta^{13} \mathrm{CH}_{3} \mathrm{D}$ at a temperature below ca. $100{ }^{\circ} \mathrm{C}$ but estimates form different levels of theory agree well (Webb and Miller, 2014; Liu and Liu, 2016).

\section{APPENDIX C. SUPPLEMENTARY MATERIAL}

Supplementary data to this article can be found online at https://doi.org/10.1016/j.gca.2020.10.015.

\section{REFERENCES}

Ash J. L., Egger M., Treude T., Kohl I., Cragg B., Parkes R. J., Slomp C. P., Lollar B. S. and Young E. D. (2019) Exchange catalysis during anaerobic methanotrophy revealed by ${ }^{12} \mathrm{CH}_{2} \mathrm{D}_{2}$ and ${ }^{13} \mathrm{CH}_{3} \mathrm{D}$ in methane. Geochem. Perspect. Lett. 10, 26-30.

Bigeleisen J. (1955) Statistical mechanics of isotopic systems with small quantum corrections. I. General considerations and the rule of the geometric mean. J. Chem. Phys. 23(12), 2264-2267. https://doi.org/10.1063/1.1740735.

Bigeleisen J. and Mayer M. G. (1947) Calculation of equilibrium constants for isotopic exchange reactions. J. Chem. Phys. 15, 261-267.

Botz R., Pokojski H.-D., Schmitt M. and Thomm M. (1996) Carbon isotope fractionation during bacterial methanogenesis by $\mathrm{CO}_{2}$ reduction. Org. Geochem. 25(3-4), 255-262. https://doi. org/10.1016/S0146-6380(96)00129-5.

Borowski W. S., Paull C. K. and Ussier W. (1997) Carbon cycling within the upper methanogenic zone of continental rise sediments: An example from the methane-rich sediments overlying the blake ridge gas hydrate deposits. Mar. Chem. 57, 299-311.

Buffett B. and Archer D. (2004) Global inventory of methane clathrate: Sensitivity to changes in the deep ocean. Earth Planet. Sci. Lett. 227, 185-199.

Canfield D. and Thamdrup B. (1994) The production of 34Sdepleted sulfide during bacterial disproportionation of elemental sulfur. Science 266(5193), 1973-1975. https://doi.org/ 10.1126/science: 11540246.

Coleman D. D., Risatti J. B. and Schoell M. (1981) Fractionation of carbon and hydrogen isotopes by methane-oxidizing bacteria. Geochim. Cosmochim. Acta 45, 1033-1037.

Coplen T. B. (2011) Guidelines and recommended terms for expression of stable-isotope-ratio and gas-ratio measurement results. Rapid Commun. Mass Spectrom. 25, 2538-2560.

Cord-Ruwisch R. (1985) A quick method for the determination of dissolved and precipitated sulfides in cultures of sulfate-reducing bacteria. J. Microbiol. Methods 4, 33-36.

Dijkstra N., Hagens M., Egger M. and Slomp C. P. (2018) Postdepositional formation of vivianite-type minerals alters sediment phosphorus records. Biogeosciences 15(3), 861-883. https://doi.org/10.5194/bg-15-861-2018-supplement.

Douglas P. M. J., Stolper D. A., Eiler J. M., Sessions A. L., Lawson M., Shuai Y., Bishop A., Podlaha O. G., Ferreira A. A., Santos Neto E. V., Niemann M., Steen A. S., Huang L., Chimiak L., Valentine D. L., Fiebig J., Luhmann A. J., Seyfried, Jr., W. E., Etiope G., Schoell M., Inskeep W. P., Moran J. J. and Kitchen N. (2017) Methane clumped isotopes: Progress and potential for a new isotopic tracer. Org. Geochem. 113, 262-282. https://doi.org/10.1016/j.orggeochem. 2017.07.016. 
Douglas P. M. J., Gonzalez M. R., Walter Anthony K. M., Wik M., Crill P. M., Dawson K. S., Smith D. A., Yanay E., Lloyd M. K., Stolper D. A., Eiler J. M. and Sessions A. L. (2020) Clumped isotopes link older carbon substrates with slower rates of methanogenesis in northern lakes. Geophys. Res. Lett. 47, 1-10.

Eldridge D. L., Korol R., Lloyd M. K., Turner A. C., Webb M. A., Miller T. F. and Stolper D. A. (2019) Comparison of experimental vs theoretical abundances of ${ }^{13} \mathrm{CH}_{3} \mathrm{D}$ and ${ }^{12} \mathrm{CH}_{2} \mathrm{D}_{2}$ for isotopically equilibrated systems from 1 to $500^{\circ} \mathrm{C}$. ACS Earth Sp. Chem. 3, 2747-2764.

Giunta T., Young E. D., Warr O., Kohl I., Ash J. L., Martini A., Mundle S. O. C., Rumble D., Pérez-Rodríguez I., Wasley M., LaRowe D. E., Gilbert A. and Sherwood Lollar B. (2019) Methane sources and sinks in continental sedimentary systems: New insights from paired clumped isotopologues ${ }^{13} \mathrm{CH}_{3} \mathrm{D}$ and ${ }^{12} \mathrm{CH}_{2} \mathrm{D}_{2}$. Geochim. Cosmochim. Acta 245, 327-351. https://doi. org/10.1016/j.gca.2018.10.030.

Gordon M. S. and Schmidt M. W. (2005) Advances in electronic structure theory: GAMESS a decade later. Theory Appl. Comput. Chem., 1167-1189.

Gruen D. S., Wang D. T., Könneke M., Topçuoğlu B. D., Stewart L. C., Goldhammer T., Holden J. F., Hinrichs K.-U. and Ono S. (2018) Experimental investigation on the controls of clumped isotopologue and hydrogen isotope ratios in microbial methane. Geochim. Cosmochim. Acta 237, 339-356.

Haghnegahdar M. A., Schauble E. A. and Young E. D. (2017) A model for ${ }^{12} \mathrm{CH}_{2} \mathrm{D}_{2}$ and ${ }^{13} \mathrm{CH}_{3} \mathrm{D}$ as complementary tracers for the budget of atmospheric $\mathrm{CH}_{4}$. Global Biogeochem. Cycles 31, 1387-1407.

Hallam S. J., Putnam N., Preston C. M., Detter J. C., Rokhsar D., Richardson P. H. and DeLong E. F. (2004) Reverse methanogenesis: Testing the hypothesis with environmental genomics. Science 305, 1457-1462.

Heller C., Hoppert M. and Reitner J. (2008) Immunological localization of coenzyme $\mathrm{M}$ reductase in anaerobic methaneoxidizing archaea of ANME 1 and ANME 2 type. Geomicrobiol. J. 25, 149-156.

Hermes Jeffrey D., Morrical Scott W., O’Leary Marion H. and Cleland W. W. (1984) Variation of transition-state structure as a function of the nucleotide in reactions catalyzed by dehydrogenases. 2. Formate dehydrogenase. Biochemistry 23(23), 54795488. https://doi.org/10.1021/bi00318a016.

Heskey P. W. and Schowen R. L. (1983) Reaction-coordinate tunneling in hydrite-transfer reactions. J. Am. Chem. Soc. 105, 5704-5706.

Holler T., Wegener G., Knittel K., Boetius A., Brunner B., Kuypers M. M. M. and Widdel F. (2009) Substantial ${ }^{13} \mathrm{C} /{ }^{12} \mathrm{C}$ and $\mathrm{D} / \mathrm{H}$ fractionation during anaerobic oxidation of methane by marine consortia enriched in vitro. Environ. Microbiol. Rep. 1, 370-376.

Holler T., Widdel F., Knittel K., Amann R. and Kellermann M. Y, Hinrichs K.-U., Teske A., Boetius A. and Wegener G. (2011a) Thermophilic anaerobic oxidation of methane by marine microbial consortia. ISME J. 5(12), 1946-1956. https://doi.org/ 10.1038/ismej.2011.77.

Holler T., Wegener G., Niemann H., Deusner C., Ferdelman T. G., Boetius A., Brunner B. and Widdel F. (2011b) Carbon and sulfur back flux during anaerobic microbial oxidation of methane and coupled sulfate reduction. Proc. Natl. Acad. Sci. 108(52), E1484-E1490. https://doi.org/10.1073/pnas. 1106032108 .

Horita J. and Wesolowski D. J. (1994) Liquid-vapor fractionation of oxygen and hydrogen isotopes of water from the freezing to the critical temperature. Geochim. Cosmochim. Acta 58, 34253437.
Huang S.-P., Shiota Y. and Yoshizawa K. (2013) DFT study of the mechanism for methane hydroxylation by soluble methane monooxygenase (sMMO): effects of oxidation state, spin state, and coordination number. Dalton Trans. 42(4), 1011-1023. https://doi.org/10.1039/C2DT31304A.

Inagaki F., Hinrichs K. U., Kubo Y., Bowles M. W., Heuer V. B., Hong W. L., Hoshino T., Ijiri A., Imachi H., Ito M., Kaneko M., Lever M. A., Lin Y. S., Methé B. A., Morita S., Morono Y., Tanikawa W., Bihan M., Bowden S. A., Elvert M., Glombitza C., Gross D., Harrington G. J., Hori T., Li K., Limmer D., Liu C. H., Murayama M., Ohkouchi N., Ono S., Park Y. S., Phillips S. C., Prieto-Mollar X., Purkey M., Riedinger N., Sanada Y., Sauvage J., Snyder G., Susilawati R., Takano Y., Tasumi E., Terada T., Tomaru H., TrembathReichert E., Wang D. T. and Yamada Y. (2015) Exploring deep microbial life in coal-bearing sediment down to $\sim 2.5 \mathrm{~km}$ below the ocean floor. Science 349, 420-424.

Joelsson L. M. T., Forecast R., Schmidt J. A., Meusinger C., Nilsson E. J. K., Ono S. and Johnson M. S. (2014) Relative rate study of the kinetic isotope effect in the $13 \mathrm{CH} 3 \mathrm{D}+\mathrm{Cl}$ reaction. Chem. Phys. Lett. 605-606, 152-157. https://doi.org/10.1016/j. cplett.2014.05.022.

Joelsson L. M. T., Schmidt J. A., Nilsson E. J. K., Blunier T., Griffith D. W. T., Ono S. and Johnson M. S. (2016) Kinetic isotope effects of ${ }^{12} \mathrm{CH}_{3} \mathrm{D}+\mathrm{OH}$ and ${ }^{13} \mathrm{CH}_{3} \mathrm{D}+\mathrm{OH}$ from 278 to 313K. Atmos. Chem. Phys. 16, 4439-4449.

Kai F. M., Tyler S. C., Randerson J. T. and Blake D. R. (2011) Reduced methane growth rate explained by decreased Northern Hemisphere microbial sources. Nature 476(7359), 194-197. https://doi.org/10.1038/nature10259.

Kaster A. K., Moll J., Parey K. and Thauer R. K. (2011) Coupling of ferredoxin and heterodisulfide reduction via electron bifurcation in hydrogenotrophic methanogenic archaea. Proc. Natl. Acad. Sci. U. S. A. 108, 2981-2986.

Kinnaman F. S., Valentine D. L. and Tyler S. C. (2007) Carbon and hydrogen isotope fractionation associated with the aerobic microbial oxidation of methane, ethane, propane and butane. Geochim. Cosmochim. Acta 71, 271-283.

Klein F., Grozeva N. G. and Seewald J. S. (2019) Abiotic methane synthesis and serpentinization in olivine-hosted fluid inclusions. Proc. Natl. Acad. Sci. 116, 17666-17672.

Knittel K. and Boetius A. (2009) Anaerobic oxidation of methane: progress with an unknown process. Annu. Rev. Microbiol. 63(1), 311-334. https://doi.org/10.1146/annurev. micro.61.080706.093130.

Knittel K., Wegener G. and Boetius A. (2019) Anaerobic methane oxidizers. In Microbial Communities Utilizing Hydrocarbons and Lipids: Members, Metagenomics and Ecophysiology (ed. Terry J. McGenity). Springer International Publishing, Cham, pp. 113132. https://doi.org/10.1007/978-3-030-14785-3_7.

Krukenberg V., Riedel D., Gruber-Vodicka H. R., Buttigieg P. L., Tegetmeyer H. E., Boetius A. and Wegener G. (2018) Gene expression and ultrastructure of meso- and thermophilic methanotrophic consortia. Environ. Microbiol. 20, 1651-1666.

Laso-Pérez R., Krukenberg V., Musat F. and Wegener G. (2018) Establishing anaerobic hydrocarbon-degrading enrichment cultures of microorganisms under strictly anoxic conditions. Nat. Protoc. 13(6), 1310-1330. https://doi.org/10.1038/nprot. 2018.030.

Liu Q. and Liu Y. (2016) Clumped-isotope signatures at equilibrium of $\mathrm{CH} 4, \mathrm{NH} 3, \mathrm{H} 2 \mathrm{O}, \mathrm{H} 2 \mathrm{~S}$ and $\mathrm{SO} 2$. Geochim. Cosmochim. Acta 175, 252-270.

Marlow J. J., Steele J. A., Ziebis W., Scheller S., Case D., Reynard L. M., Orphan V. J. and Green Tringe S. (2017). Monodeuterated methane, an isotopic tool to assess biological methane 
metabolism rates. mSphere 2(4). https://doi.org/10.1128/ mSphereDirect.00309-17.

Mariotti A., Germon J. C., Hubert P., Kaiser P., Letolle R., Tardieux A. and Tardieux P. (1981) Experimental determination of nitrogen kinetic isotope fractionation: Some principles; illustration for the denitrification and nitrification processes. Plant Soil 62(3), 413-430. https://doi.org/10.1007/BF02374138.

McDermott J. M., Seewald J. S., German C. R. and Sylva S. P. (2015) Pathways for abiotic organic synthesis at submarine hydrothermal fields. Proc. Natl. Acad. Sci. U. S. A. 112, 76687672.

Meyerdierks A., Kube M., Kostadinov I., Teeling H., Glöckner F. O., Reinhardt R. and Amann R. (2010) Metagenome and mRNA expression analyses of anaerobic methanotrophic archaea of the ANME-1 group. Environ. Microbiol. 12, 422439.

Milkov A. V. (2004) Global estimates of hydrate-bound gas in marine sediments: How much is really out there? Earth-Sci. Rev. 66, 183-197.

Okumura T., Kawagucci S., Saito Y., Matsui Y., Takai K. and Imachi H. (2016) Hydrogen and carbon isotope systematics in hydrogenotrophic methanogenesis under $\mathrm{H}_{2}$-limited and $\mathrm{H}_{2}$ enriched conditions: Implications for the origin of methane and its isotopic diagnosis. Prog. Earth Planet. Sci. 3, 2-15.

Ono S., Wang D. T., Gruen D. S., Sherwood Lollar B., Zahniser M. S., McManus B. J. and Nelson D. D. (2014) Measurement of a doubly substituted methane isotopologue, ${ }^{13} \mathrm{CH}_{3} \mathrm{D}$, by tunable infrared laser direct absorption spectroscopy. Anal. Chem. 86, 6487-6494.

Pohlman J. W., Ruppel C., Hutchinson D. R., Downer R. and Coffin R. B. (2008) Assessing sulfate reduction and methane cycling in a high salinity pore water system in the northern Gulf of Mexico. Mar. Pet. Geol. 25, 942-951.

Powelson D. K., Chanton J. P. and Abichou T. (2007) Methane oxidation in biofilters measured by mass-balance and stable isotope methods. Environ. Sci. Technol. 41(2), 620-625. https:// doi.org/10.1021/es061656g.s001.

Reeburgh W. S. (2007) Oceanic methane biogeochemistry. Chem. Rev. 107, 486-513.

Richet P., Bottinga Y. and Javoy M. (1977) A review of hydrogen, carbon, nitrogen, oxygen, sulphur, and chlorine stable isotope fractionation among gaseous molecules. Annu. Rev. Earth Planet. Sci. 5, 65-110.

Rigby M., Manning A. J. and Prinn R. G. (2012) The value of high-frequency, high-precision methane isotopologue measurements for source and sink estimation. J. Geophys. Res. 117 (D12), n/a-n/a. https://doi.org/10.1029/2011JD017384.

Rucker J. and Klinman J. P. (1999) Computational study of tunneling and coupled motion in alcohol dehydrogenasecatalyzed reactions: Implication for measured hydrogen and carbon isotope effects. J. Am. Chem. Soc. 121, 1997-2006.

Scharschmidt M., Fisher M. A. and Cleland W. W. (1984) Variation of transition-state structure as a function of the nucleotide in reactions catalyzed by dehydrogenases. 1. Liver alcohol dehydrogenase with benzyl alcohol and yeast aldehyde dehydrogenase with benzaldehyde. Biochemistry 23(23), 54715478. https://doi.org/10.1021/bi00318a015.

Scheller S., Goenrich M., Boecher R., Thauer R. K. and Jaun B. (2010) The key nickel enzyme of methanogenesis catalyses the anaerobic oxidation of methane. Nature 465(7298), 606-608. https://doi.org/10.1038/nature09015.

Scheller S., Goenrich M., .Thauer R. K. and Jaun B. (2013) Methyl-coenzyme $\mathrm{M}$ reductase from methanogenic archaea: isotope effects on the formation and anaerobic oxidation of methane. J. Am. Chem. Soc. 135(40), 14975-14984. https://doi. org/10.1021/ja406485z.
Schoell M. (1980) The hydrogen and carbon isotopic composition of methane from natural gases of various origins. Geochim. Cosmochim. Acta 44, 649-661.

Shima S. and Thauer R. K. (2005) Methyl-coenzyme M reductase and the anaerobic oxidation of methane in methanotrophic Archaea. Curr. Opin. Microbiol. 8, 643-648.

Sim M. S., Bosak T. and Ono S. (2011) Large sulfur isotope fractionation does not require disproportionation. Science $\mathbf{3 3 3}$ (6038), 74-77. https://doi.org/10.1126/science:1205103.

Singh P., Islam Z. and Kohen A. (2016) Examinations of the chemical step in enzyme catalysis. In Computational Approaches for Studying Enzyme Mechanism Part A. Academic Press, pp. 287-318.

Sivan O., Schrag D. P. and Murray R. W. (2007) Rates of methanogenesis and methanotrophy in deep-sea sediments. Geobiology 5(2), 141-151. https://doi.org/10.1111/j.14724669.2007.00098.x.

Stolper D. A., Lawson M., Davis C. L., Ferreira A. A., Santos Neto E. V., Ellis G. S., Lewan M. D., Martini A. M., Tang Y., Schoell M., Sessions A. L. and Eiler J. M. (2014a) Formation temperatures of thermogenic and biogenic methane. Science 344, 1500-1503.

Stolper D. A., Sessions A. L., Ferreira A. A., Santos Neto E. V., Schimmelmann A., Shusta S. S., Valentine D. L. and Eiler J. M. (2014b) Combined 13C-D and D-D clumping in methane: Methods and preliminary results. Geochim. Cosmochim. Acta 126, 169-191.

Stolper D. A., Martini A. M., Clog M., Douglas P. M., Shusta S. S., Valentine D. L., Sessions A. L. and Eiler J. M. (2015) Distinguishing and understanding thermogenic and biogenic sources of methane using multiply substituted isotopologues. Geochim. Cosmochim. Acta 161, 219-247.

Thauer R. K. (2011) Anaerobic oxidation of methane with sulfate: On the reversibility of the reactions that are catalyzed by enzymes also involved in methanogenesis from $\mathrm{CO}_{2}$. Curr. Opin. Microbiol. 14, 292-299.

Thauer R. K., Kaster A. K., Seedorf H., Buckel W. and Hedderich R. (2008) Methanogenic archaea: Ecologically relevant differences in energy conservation. Nat. Rev. Microbiol. 6, 579-591.

Thauer R. K., Kaster A.-K., Goenrich M., Schick M., Hiromoto T. and Shima S. (2010) Hydrogenases from methanogenic archaea, nickel, a novel cofactor, and $\mathrm{H}_{2}$ storage. Annu. Rev. Biochem. 79, 507-536.

Tissot B., Durand B., Espitalie J. and Combaz A. (1974) Influence of nature and diagenesis of organic matter in formation of petroleum. Am. Assoc. Pet. Geol. Bull. 58, 499-506.

Urey H. C. (1947) The thermodynamic properties of isotopic substances. J. Chem. Soc., 562-581.

Valentine D. L., Chidthaisong A., Rice A., Reeburgh W. S. and Tyler S. C. (2004) Carbon and hydrogen isotope fractionation by moderately thermophilic methanogens. Geochim. Cosmochim. Acta 68, 1571-1590.

Wang D. T., Gruen D. S., Sherwood Lollar B., Hinrichs K.-U., Stewart L. C., Holden J. F., Hristov A. N., Pohlman J. W., Morrill P. L., Könneke M., Delwiche K. B., Reeves E. P., Sutcliffe C. N., Ritter D. J., Seewald J. S., McIntosh J. C., Hemond H. F., Kubo M. D., Cardace D., Hoehler T. M. and Ono S. (2015) Nonequilibrium clumped isotope signals in microbial methane. Science 348, 428-431.

Wang D. T., Welander P. V. and Ono S. (2016) Fractionation of the methane isotopologues ${ }^{13} \mathrm{CH}_{4},{ }^{12} \mathrm{CH}_{3} \mathrm{D}$, and ${ }^{13} \mathrm{CH}_{3} \mathrm{D}$ during aerobic oxidation of methane by Methylococcus capsulatus (Bath). Geochim. Cosmochim. Acta 192, 186-202.

Wang D. T., Reeves E. P., McDermott J. M., Seewald J. S. and Ono S. (2018) Clumped isotopologue constraints on the origin 
of methane at seafloor hot springs. Geochim. Cosmochim. Acta 223, 141-158.

Wang Y., Sessions A. L., Nielsen R. J. and Goddard W. A. (2009) Equilibrium ${ }^{2} \mathrm{H} /{ }^{1} \mathrm{H}$ fractionations in organic molecules: I. Experimental calibration of ab initio calculations. Geochim. Cosmochim. Acta 73, 7060-7075.

Webb M. A. and Miller T. F. (2014) Position-specific and clumped stable isotope studies: Comparison of the urey and pathintegral approaches for carbon dioxide, nitrous oxide, methane, and propane. J. Phys. Chem. A 118, 467-474.

Wegener G., Krukenberg V., Ruff S. E., Kellermann M. Y. and Knittel K. (2016) Metabolic capabilities of microorganisms involved in and associated with the anaerobic oxidation of methane. Front. Microbiol. 7, 1-16.

Whitehill A. R., Joelsson L. M. T., Schmidt J. A., Wang D. T., Johnson M. S. and Ono S. (2017) Clumped isotope effects during $\mathrm{OH}$ and $\mathrm{Cl}$ oxidation of methane. Geochim. Cosmochim. Acta 196, 307-325.

Whiticar M. J. (1999) Carbon and hydrogen isotope systematics of bacterial formation and oxidation of methane. Chem. Geol. 161, 291-314.

Whiticar M. and Schaefer H. (2007) Constraining past global tropospheric methane budgets with carbon and hydrogen isotope ratios in ice. Philos. Trans. R. Soc. A Math. Phys. Eng. Sci. 365, 1793-1828.

Wilhelms A., Larter S. R., Head I., Farrimond P., Di-Primio R. and Zwach C. (2001) Biodegradation of oil in up lifted basins prevented by deep-burial sterilization. Nature 411, 1034-1037.
Wongnate T., Sliwa D., Ginovska B., Smith D., Wolf M. W., Lehnert N., Raugei S. and Ragsdale S. W. (2016) The radical mechanism of biological methane synthesis by methylcoenzyme M reductase. Science 352, 953-958.

York D., Evensen N. M., Martı'nez M. L. and De Basabe Delgado J. (2004) Unified equations for the slope, intercept, and standard errors of the best straight line. Am. J. Phys. 72, 367375.

Yoshinaga M. Y., Holler T., Goldhammer T., Wegener G., Pohlman J. W., Brunner B., Kuypers M. M. M., Hinrichs K. U. and Elvert M. (2014) Carbon isotope equilibration during sulphate-limited anaerobic oxidation of methane. Nat. Geosci. 7, 190-194.

Young E. D., Kohl I. E., Lollar B. S., Etiope G., Rumble D., Li (李 姝宁) S., Haghnegahdar M. A., Schauble E. A., McCain K. A., Foustoukos D. I., Sutclife C., Warr O., Ballentine C. J., Onstott T. C., Hosgormez H., Neubeck A., Marques J. M., PérezRodríguez I., Rowe A. R., LaRowe D. E., Magnabosco C., Yeung L. Y., Ash J. L. and Bryndzia L. T. (2017) The relative abundances of resolved ${ }^{12} \mathrm{CH}_{2} \mathrm{D}_{2}$ and ${ }^{13} \mathrm{CH}_{3} \mathrm{D}$ and mechanisms controlling isotopic bond ordering in abiotic and biotic methane gases. Geochim. Cosmochim. Acta 203, 235-264.

Associate editor: Ann Pearson 